IZA DP No. 7340

How Do Voters Respond to Information? Evidence from a Randomized Campaign

Chad Kendall

Tommaso Nannicini

Francesco Trebbi

April 2013 


\title{
How Do Voters Respond to Information? Evidence from a Randomized Campaign
}

\author{
Chad Kendall \\ University of British Columbia \\ Tommaso Nannicini \\ Bocconi University, \\ IGIER and IZA \\ Francesco Trebbi \\ University of British Columbia, \\ CIFAR and NBER
}

Discussion Paper No. 7340
April 2013

IZA

P.O. Box 7240

53072 Bonn

Germany

Phone: +49-228-3894-0

Fax: +49-228-3894-180

E-mail: iza@iza.org

Any opinions expressed here are those of the author(s) and not those of IZA. Research published in this series may include views on policy, but the institute itself takes no institutional policy positions. The IZA research network is committed to the IZA Guiding Principles of Research Integrity.

The Institute for the Study of Labor (IZA) in Bonn is a local and virtual international research center and a place of communication between science, politics and business. IZA is an independent nonprofit organization supported by Deutsche Post Foundation. The center is associated with the University of Bonn and offers a stimulating research environment through its international network, workshops and conferences, data service, project support, research visits and doctoral program. IZA engages in (i) original and internationally competitive research in all fields of labor economics, (ii) development of policy concepts, and (iii) dissemination of research results and concepts to the interested public.

IZA Discussion Papers often represent preliminary work and are circulated to encourage discussion. Citation of such a paper should account for its provisional character. A revised version may be available directly from the author. 


\section{ABSTRACT \\ How Do Voters Respond to Information? Evidence from a Randomized Campaign*}

Rational voters update their subjective beliefs about candidates' attributes with the arrival of information, and subsequently base their votes on these beliefs. Information accrual is, however, endogenous to voters' types and difficult to identify in observational studies. In a large scale randomized trial conducted during an actual mayoral campaign in Italy, we expose different areas of the polity to controlled informational treatments about the valence and ideology of the incumbent through verifiable informative messages sent by the incumbent reelection campaign. Our treatments affect both actual vote shares at the precinct level and vote declarations at the individual level. We explicitly investigate the process of belief updating by comparing the elicited priors and posteriors of voters, finding heterogeneous responses to information. Based on the elicited beliefs, we are able to structurally assess the relative weights voters place upon a candidate's valence and ideology. We find that both valence and ideological messages affect the first and second moments of the belief distribution, but only campaigning on valence brings more votes to the incumbent. With respect to ideology, cross-learning occurs, as voters who receive information about the incumbent also update their beliefs about the opponent. Finally, we illustrate how to perform counterfactual campaigns based upon the structural model.

JEL Classification: D72, D83

Keywords: voting, information, beliefs elicitation, randomized controlled trial

Corresponding author:

Tommaso Nannicini

Department of Economics

Bocconi University

Via Roentgen 1

20136 Milan

Italy

E-mail: tommaso.nannicini@unibocconi.it

\footnotetext{
* We would like to thank Matilde Bombardini, David Green, Andrea Mattozzi, Jim Snyder, and seminar participants at Alicante, Bank of Italy, Bocconi, Carlo Alberto Turin, EIEF Rome, Harvard, LSE, MILLS workshop, MIT, Petralia workshop, Rotterdam, SciencesPo Paris, UBC, UK Leuven, and Warwick for useful comments. Federico Cilauro, Francesco Maria Esposito, Jonathan Graves, Nicola Pierri, and Teresa Talò provided outstanding research assistance. A large number of people were instrumental in implementing our experimental design: the mayor of Arezzo, Giuseppe Fanfani, and his 2011 reelection campaign, in particular Claudio Repek, were extremely cooperative throughout the entire process; Massimo Di Filippo, Fabrizio Monaci, and the team of "IPR Feedback" showed tremendous expertise in conducting the surveys. Nannicini acknowledges financial support from the European Research Council (under grant No. 230088). Remaining errors are ours and follow a random walk.
} 


\section{Introduction}

We study the causal impact of campaign information on electoral outcomes and voters' beliefs about political candidates in the context of a large field experiment encompassing an entire electoral campaign. In collaboration with the incumbent mayor of a medium-sized Italian city who was running for reelection in 2011, eligible voters received hard and verifiable information, via mail or phone, about the valence or the ideological stance of the incumbent. The city was randomly divided into four areas, with the first receiving a campaign message about valence, the second about ideology, the third about both valence and ideology, and the fourth receiving no message at all. The informational treatments were administered by the incumbent as part of his campaign. Our direct mailing covered the entire voting population and our phone bank covered about a quarter of all households in the city. Moreover, voters received only our mailers from the incumbent campaign, and only our phone calls from both the incumbent and the main challenger's campaign.

Relative to the control group that received no campaign message, voters informed about the valence of the incumbent - via both mail and phone - increased their support for the candidate by 4.1 percentage points as measured by precinct-level official vote shares, and by 9.5 percentage points as measured by vote declarations in surveys. Much weaker effects on vote choices were detected when information about the ideological stance of the incumbent was provided, or when campaigning was done by mail only. To the best of our knowledge, this is the first time evidence from an entire election has been used to answer the question of whether or not campaign information causally influences actual electoral outcomes in a mature democracy.

This paper is not limited to the analysis of vote choices in the context of a randomized controlled trial. Our goal is to show the extent of the response of individual agents to political messages and to understand the degree of sophistication in their subjective updating. The empirical application revolves around the assessment of the role of campaign ads in elections, but the point is more general than political advertising. Our methodology can extend to other forms of direct communication by politicians to voters, has implications beyond the political environment, and is of interest for commercial advertising - or for any other type of informational treatment - as well.

Using a novel elicitation protocol, we collected information about the distributions of individual voters' (multivariate) beliefs about the valence and ideological stance of both the incumbent and the main challenger through surveys both before and after the informational treatments were administered. We show how, by imposing a limited amount of structure on electoral preferences and belief distributions, prior and posterior beliefs of individual voters can be fully characterized. We 
also show that, although only valence treatments were effective in changing votes, our informational treatments along both the valence and ideological dimension had large effects on voters' beliefs, moving both first and second moments of the belief distributions for the two main candidates. Indeed, campaign information affected not only voters' beliefs about the candidate originating the message, but also their beliefs about the opponent. Intuitively, in Bayesian signaling games, receiving no message is valuable information and our evidence on cross-learning appears fully consistent with updating in the context of a Bayesian political signaling game.

The full characterization of the individual belief distributions we propose is the combination of a careful design of our surveys and structural estimation of a random utility voting model. The latter component of our methodology delivers precise estimates of utility weights in voters' preferences for a candidate's valence and ideology. We report a utility weight on valence roughly equal to that on ideological losses away from a voter's bliss point. Interestingly, we also show that the preference weights are heterogeneous in the population and depend on the political stance of the voter, with voters on the right placing less emphasis on the valence dimension. Finally, we show that the ideological loss function away from the voter's bliss point is concave in distance, not convex (e.g., quadratic losses) as commonly assumed in the literature.

The random utility model we use follows the method outlined in the theoretical paper of Ramalho and Smith (2012) to account for non-randomness in voters' willingness to disclose their votes. While non-response in survey data is often assumed to be random, we demonstrate the importance of accounting for its endogeneity and suggest that this method should be more often utilized in empirical studies in which survey responses are relied upon.

We conclude our analysis by simulating counterfactual electoral campaigns to assess the effects of specific blanket or targeted electoral campaigns on vote outcomes. We find a blanket campaign of valence messages to be the most valuable in persuading voters, which is consistent with voters lacking prior information on the quality of candidates.

This paper is related to several strands of the literature. The effectiveness of electoral campaigns in mature democracies is the subject of a large literature, including Ansolabehere et al. (1994), Ansolabehere and Iyengar (1995), Gerber and Green (2000), Green and Gerber (2004), Gerber, Green, and Shachar (2003), Nickerson (2008), and Dewan, Humphreys, and Rubenson (2010). Typically the focus of these papers is either on self-declared outcomes for vote choices or on actual outcomes for turnout. Methodologically, these papers rely on either small-scale experiments for partisan ads or on randomized non-partisan campaigns for turnout. Our paper complements this literature by focusing on actual electoral outcomes in a large scale field experiment. We must clarify 
that our paper is not the first instance of a large scale randomized partisan campaign. Gerber et al. (2011) look at randomization over intensity of TV ads (with no control over the message content) on self-declared choices during the 2006 Republican primary for the Texas gubernatorial election. They find large, but short-lived, effects of such TV ads, inconsistent with Bayesian updating. Unlike their approach, we randomize the content of partisan ads and also evaluate their impact on actual vote shares. Our paper also complements this literature from a methodological standpoint by augmenting the reduced form approach with structural estimation.

Albeit in the context of less mature democracies, the literature in development economics has also experimented with informational campaigning. Relevant contributions include Wantchekon (2003) and Fujiwara and Wantchekon (2013), exploring political clientelism in Benin, Vicente (2013), and Banerjee, Green, and Pande (2012). Banerjee et al. (2011) focus on non-partisan informational campaigns in India and show that information about the qualifications of candidates matters for turnout, vote shares, and the incidence of vote buying.

This paper is related to a vast literature on candidate's valence, initiated by Stokes (1963) and including Enelow and Hinich (1982), Ansolabehere and Snyder (2000), Groseclose (2001), Schofield (2003), Aragones and Palfrey (2002) among others. More recently, Ashworth and Bueno de Mesquita (2009), Kartik and McAfee (2007), and Bernhardt, Camara, and Squintani (2011) provide interesting theoretical studies of strategic electoral competition with candidates differentiated along both (ideological) policy platform and valence dimensions. Galasso and Nannicini (2011) study the interplay between candidates' valence and the contestability of electoral districts.

Finally, this paper contributes to the growing literature focused on the elicitation and quantification of subjective beliefs. Elicitation of priors is the subject of Dominitz and Manski (1996), Manski (2004), Blass, Lach, and Manski (2010), Gill and Walker (2005), and Duffy and Tavits (2008) among others. To these contributions, which mostly focus on the elicitation of expectations of economic outcomes, our work provides a useful addition in the context of the elicitation of multivariate beliefs. In particular, we show how to decouple information about marginal beliefs and their dependence using a copula function approach. We believe this approach may be of use outside the politico-economic application in our study.

The rest of the paper is organized as follows. Section 2 presents the empirical model. Section 3 describes the experimental setting. Section 4 discusses the reduced form results on vote choices. Section 5 focuses on the structural estimates of the model and Section 6 on the experimental effects on voters' beliefs. Section 7 presents our counterfactuals and discusses the implications of the heterogeneous response to information on the part of voters. Section 8 concludes. 


\section{Empirical Model}

\subsection{Voters and Candidates}

Consider an electoral race between two candidates, $A$, the incumbent, and $B$, the challenger. Let the set of voters be $\mathcal{N}$, with $|\mathcal{N}|=N$. A voter $i$ is characterized by an ideal policy point distributed over a finite and discrete policy space, $\Pi$, which is common across all voters, with policies $P \in \Pi$. The discreteness assumption is meant to capture an empirical feature of the survey data employed in the subsequent analysis. Voters are heterogeneous, with bliss points $q \in \Pi$, and receive disutility from a policy choice away from their bliss point. They also receive utility from the level of valence of the elected candidate $V \in \Lambda$, where the set $\Lambda$ is finite and discrete. When policy $p$ is implemented by candidate $j$ of valence $v$, the utility for voter $i$ of type $q$ is assumed to be:

$$
U(v, p ; q)=\gamma v-u(q-p)-\chi u(q-p) v+\varepsilon_{i, j}
$$

where the utility function includes a deterministic portion and a candidate-specific random utility component $\varepsilon_{i, j}$, independent of $V$ and $P$. The parameter $\gamma$ indicates the relative preference weight of valence versus the policy stance. We assume $u(0)=0, u^{\prime}(x) \geq 0$ for $x>0$, and $u^{\prime}(x) \leq 0$ for $x<0$. For example, a quadratic loss away from voter $i$ 's bliss point, $\left(q_{i}-p\right)^{2}$, fits this set of assumptions. ${ }^{1}$ However, we assume the more general form $u(x)=|x|^{\zeta}$ with $\zeta \geq 0$. The policy stance of the politician, $p$, affects voters heterogeneously depending upon their own ideal position, $q$, but candidates of higher quality $v$ are favored by all voters. We also allow for interactions between valence and policy positions that are governed by $\chi$. The random utility component $\varepsilon_{i, j}$ of voter $i$ 's preferences for candidate $j$ captures the personal appeal of $j$ to $i$.

It is not important for our purposes to specify whether the two candidates $A$ and $B$ implement their respective ideal policy position $P$ once in office (see Ansolabehere, Snyder, and Stewart, 2001; Lee, Moretti, and Butler, 2004) or strategically cater their policy to voters (e.g., as in a standard Downsian setting). We are interested in the voters' utilities at the time they place their vote, which only depend upon their beliefs about each candidate's position, and not on how the policy position came about or whether or not it is actually implemented. In general, our approach is robust to the details of the electoral competition structure.

All voters participate in the election (voting is compulsory in our empirical setting). Voter $i$ is assumed to have a joint prior distribution function over $V$ and $P, f_{V, P}^{i, j}(v, p)$, for $j=A, B$, evaluated at point $(v, p)$ and defined over the support $\Lambda \times \Pi$. We do not preclude $V$ from being potentially correlated with $P$ and we allow priors to differ based upon $i$ 's characteristics or ideal point $q$.

\footnotetext{
${ }^{1}$ Quadratic loss functions are standard in the literature (e.g., see Ansolabehere and Snyder, 2000).
} 
Our experimental treatments induce a randomized change in the information sets of voters, which we describe in detail in Section 3. The discreteness of the experimental strategy induces a finite set of informational types of voters.

Type 1 : Receiving a message about $V$, but not $P$, of $A$.

Type 2 : Receiving a message about $P$, but not of $V$, of $A$.

Type 3 : Receiving a message about both $V$ and $P$ of $A$.

Type 4 : Receiving no message about $V$ or $P$ of $A$.

For simplicity, a "message" indicates having (randomly) received a campaign information treatment, $H \in\{1, \ldots, 4\}$. Let us indicate as $\mathcal{T}(h)$ the set of voters treated with information type $H=h$ and let $f_{V, P}^{i, A}(v, p \mid H=h)$ indicates the subjective posterior probability that voter $i$, treated by message $h$, assigns to the event that candidate $A$ has valence $V=v$ and position $P=p$. The process of updating beliefs typically reflects the characteristics of the game played between voters and political candidates (e.g., a signaling game). Our approach allows to leave the nature of such strategic interaction unspecified.

The expected utility from the election of $A$ for voter $i$, treated by $h$ and with ideal point $q$, is:

$$
E U_{A}^{i}\left(h, q_{i}\right)=\sum_{p} \sum_{v} f_{V, P}^{i, A}(v, p \mid H=h) U\left(v, p ; q_{i}\right)+\varepsilon_{i, A} .
$$

If, instead, $B$ is elected, the expected utility for voter of type $\left(h, q_{i}\right)$ is:

$$
E U_{B}^{i}\left(h, q_{i}\right)=\sum_{p} \sum_{v} f_{V, P}^{i, B}(v, p \mid H=h) U\left(v, p ; q_{i}\right)+\varepsilon_{i, B} .
$$

The probability that $i$ of type $(h, q)$ supports candidate $A$ is given by:

$$
\operatorname{Pr}\left[E U_{A}^{i}\left(h, q_{i}\right) \geq E U_{B}^{i}\left(h, q_{i}\right)\right] .
$$

Given the probability that a voter supports candidate $A$, we can consider a standard, conditional logit model, assuming $\varepsilon_{i j}$ to be i.i.d. across voters and distributed with a Type I extreme-value distribution with cumulative distribution function $F\left(\varepsilon_{i j}\right)=\exp \left(-e^{-\varepsilon_{i j}}\right)$. Provided information on the choice of $i$ to vote for $j, Y_{i}=j$, we obtain the loglikelihood:

$$
\ln L(\theta)=\sum_{i=1}^{N} \sum_{j} d_{i j} \ln \operatorname{Pr}\left(Y_{i}=j\right)=\sum_{i=1}^{N} \sum_{j} d_{i j} \ln \frac{e^{E U_{j}^{i}\left(h, q_{i}\right)}}{\sum_{l} e^{E U_{l}^{i}\left(h, q_{i}\right)}}
$$

where $d_{i j}$ is 1 if $i$ votes for $j$, and 0 otherwise. Note that the vector of parameters of interest, $\theta$, includes both preference parameters $[\gamma, \zeta, \chi]$ and the parameters of the joint beliefs $f_{V, P}^{i, j}($.$) , which$ we define in the following subsection. 
One potential problem with the standard logit model in a setting employing vote declarations as opposed to actual votes is that voters, when surveyed, may prefer not to disclose their vote. If the sample of voters who do not disclose their vote is completely random, one can apply the logit model to the subsample of responders. This is the approach typically followed in the literature, often without diagnostics in support of the crucial "missing completely at random" assumption, required for an unbiased estimate. We provide evidence in Section 5 that indicates that the subsample of voters that choose not to disclose their votes is predictable, so estimation of the standard logit model would lead to biased estimates in our setting. We therefore apply a novel choice-based approach suggested by Ramalho and Smith (2012) that allows for non-random non-response under weak assumptions. The model assumes that, conditional on the voter's actual vote, the probability with which a voter chooses to respond to the survey is constant, but that this probability can depend on their vote. Under this assumption, we can define the loglikelihood as:

$$
\ln L(\theta)=\sum_{i=1}^{N}\left(o_{i} \sum_{j} d_{i j} \ln \beta_{j} \frac{e^{E U_{j}^{i}\left(h, q_{i}\right)}}{\sum_{l} e^{E U_{l}^{i}\left(h, q_{i}\right)}}+\left(1-o_{i}\right) \ln \left(1-\sum_{j} \beta_{j} \frac{e^{E U_{j}^{i}\left(h, q_{i}\right)}}{\sum_{l} e^{E U_{l}^{i}\left(h, q_{i}\right)}}\right)\right)
$$

where $o_{i}$ is 1 if $i$ discloses the vote, and 0 otherwise. The additional $\beta_{j}$ parameters are the probabilities with which a voter discloses the vote for $j$. The first term of the loglikelihood is the probability that a voter votes for $j$ and discloses the vote. The second term reflects the probability that the voter votes for one of the candidates, but chooses not to disclose the vote. Note that when $\beta_{j}=1$ for all $j$, such that the vote is always observed, we obtain the standard logit model as a special case. Our results in Section 5 reject $\beta_{j}=1$ for all $j$, meaning that we are justified in accounting for the possibility of non-random non-response.

\subsection{Voters' Subjective Updating}

Here, we specify the process by which voters' subjective beliefs are updated in the presence of campaign advertising. For illustrative purposes, consider the following time line.

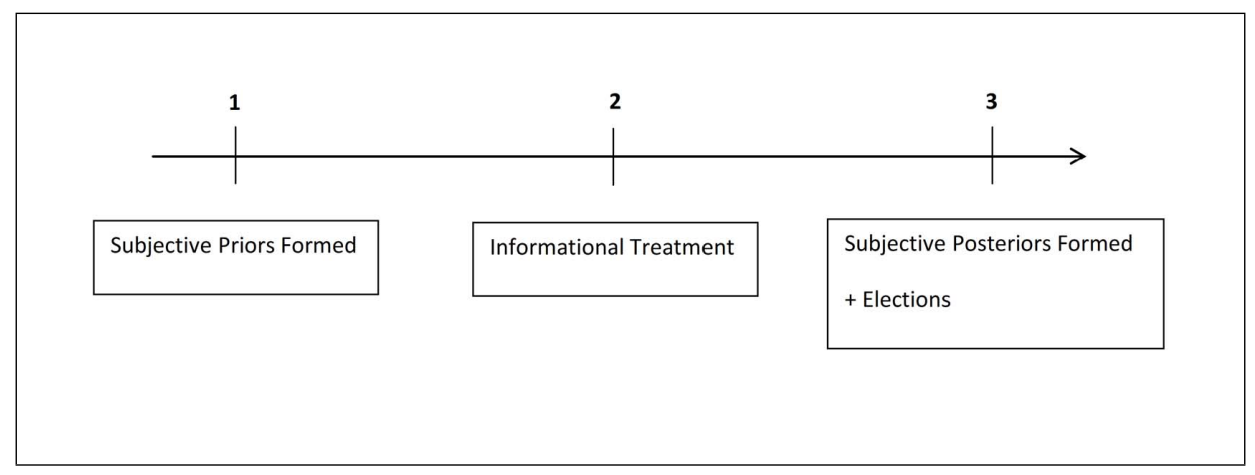


Our first assumption is that voters consider the campaign information to be truthful. Sufficient freedom of the press in the Italian electoral context guarantees that such an assumption may be valid in the case of factual advertising, as we employ in our experimental setup. All messages are factual and can be independently validated.

Secondly, we assume rational Bayesian voters. ${ }^{2}$ We refrain from imposing distributional assumptions on priors, posteriors, and on the distribution of signals. Instead, we adopt the option of eliciting subjective priors and posteriors from specifically designed surveys. This is an important step for two main reasons. First, elicitation allows us to assess quantitatively how the messaging strategy we employed experimentally operates in the field. Indeed, voters are not aware of the randomization process and update their beliefs "as if" the messages were directly sent by the candidate. This is not an assumption, but part of the experimental design. Under the assumption of Bayesian voters, belief updating about candidate $A$ implies:

$$
f_{V, P}^{i, A}(v, p \mid H=h)=\frac{\operatorname{Pr}^{i, A}(H=h \mid V=v, P=p)}{\operatorname{Pr}^{i, A}(H=h)} \times f_{V, P}^{i, A}(v, p) \quad \text { for } h=1,2,3,
$$

where the subjective updating term $\frac{\operatorname{Pr}^{i, A}(H=h \mid V=v, P=p)}{\operatorname{Pr}^{i, A}(H=h)}$ can be recovered directly from the data after elicitation of $f_{V, P}^{i, A}(v, p \mid H=h)$ and $f_{V, P}^{i, A}(v, p)$. Second, our approach allows for general strategic electoral communication between candidates and voters in the background. We are not required to model or restrict the voting game played among $\mathcal{N}, A$, and $B$. Any strategic signaling is captured by the updating term $\frac{\operatorname{Pr}^{i, A}(H=h \mid V=v, P=p)}{\operatorname{Pr}^{i, A}(H=h)}$, which we estimate, not model. ${ }^{3}$

Bayesian updating in case the voter receives no message from the candidate requires further discussion. Consider the case of a fully rational Bayesian voter that receives no campaign advertising from a candidate, but knows that such action was available. In such a case, as Chappell (1994) states, "absence of a message provides information which should be used in Bayesian updating" with the result that subjective posteriors probabilities are different from priors even absent any message having reached the voter. In the case of posteriors about candidate $B$, for instance, this requires that voter $i$ updates priors based on absence of an $H$ message from $B$. Formally:

$$
f_{V, P}^{i, B}(v, p \mid H=h) \neq f_{V, P}^{i, B}(v, p) \text { for } h=1,2,3,
$$

which is justified from voter $i$ having observed at least one extra campaign message from $A$ without any corresponding counter-message from $B$.

\footnotetext{
${ }^{2}$ Note that, while we need voters to be rational and vote sincerely, the assumption of Bayesian updating is simply convenient for the exposition, as our empirical framework allows us to identify belief updating in more general terms.

${ }^{3} \mathrm{~A}$ dynamic repeated election model with both ideological and valence considerations that would fit our problem is, for instance, proposed in Bernhardt, Camara, and Squintani (2011).
} 
The degree of rationality embedded in condition (2) cannot be extended, however, to the experimental control group $H=4$, which does not receive any type of informational treatment by either $A$ or $B$ and hence has no possibility of knowing that such specific messages would be available but were not employed. The fundamental assumption of our experimental design mirrors a Stable Unit Treatment Value Assumption (SUTVA, see Cox, 1958; Rubin, 1978), as it requires the potential outcome of a control unit to be unaffected by the treatment assignment of the other units. Absent common shocks, we should assume for $H=4$ that the posterior distribution is identical to the prior distribution, that is, for every $i \in \mathcal{T}(4), f_{V, P}^{i, j}(v, p \mid H=4)=f_{V, P}^{i, j}(v, p)$ for $j=A, B$.

More generally, we consider a process of Bayesian updating which accommodates common shocks across voters, under the (testable) assumption that the subjective probabilities on such shocks are identical across all $i \in \mathcal{N}$ and independent of $H$. Consider, for instance, the case of posteriors elicited after a common informational shock, $W$, which can be thought of as the general campaign carried out by the candidates besides the informational messages from $A$ that we randomize at the margin. With respect to candidate $j$, voter $i$ will be characterized by the following posteriors.

$$
\begin{gathered}
\text { Assumption } 1 \text { (SUTVA): } f_{V, P}^{i, j}(v, p \mid H=h, W)=\frac{\operatorname{Pr}^{i, j}(H=h \mid V=v, P=p)}{\operatorname{Pr}^{i, j}(H=h)} \\
\times \frac{\operatorname{Pr}^{j}(W \mid V=v, P=p)}{\operatorname{Pr}^{j}(W)} \times f_{V, P}^{i, j}(v, p) \text { for } h=1,2,3 ; j=A, B \\
\text { and } \\
f_{V, P}^{i, j}(v, p \mid H=4, W)=\frac{\operatorname{Pr}^{j}(W \mid V=v, P=p)}{\operatorname{Pr}^{j}(W)} \times f_{V, P}^{i, j}(v, p) \text { for } j=A, B .
\end{gathered}
$$

The credibility of Assumption 1 crucially rests on the experimental design described in Section 3 and is empirically validated in Section 4.

Finally, the elicitation of multivariate beliefs, even on expert subjects, is not an obvious exercise (Kadane and Wolfson, 1998; Garthwaite et al., 2005) and is the object of a vast literature bordering statistics and psychology (dating at least as back as Savage, 1971). We outline our approach next.

\subsection{Elicitation of Multivariate Beliefs}

Elicitation of beliefs and priors is increasingly common in economics and political science, and is standard in psychology and statistics. ${ }^{4}$ We describe a transparent protocol of elicitation we designed to be robust to the behavioral and technological constraints we face. Specifically, we sampled a large number of voters and need to elicit multivariate beliefs from each.

\footnotetext{
${ }^{4}$ For recent examples in economics, see Dominitz and Manski (1996); Manski (2004); Blass et al. (2010); and Zafar (2009). See Gill and Walker (2005) and Duffy and Tavits (2008) for applications in political science.
} 
For each main candidate $j=A, B$ and each voter $i$, joint valence and ideology subjective

priors $f_{V, P}^{i, j}(v, p)$ and posteriors $f_{V, P}^{i, j}(v, p \mid H=h)$ are defined over $\Lambda \times \Pi$. In the remainder of this subsection, let us focus for brevity on the elicitation of subjective priors, with the understanding that the same process applies to posteriors. In the empirical analysis we will fix the cardinality of both $\Lambda$ and $\Pi$ to small integer figures, based on Miller (1956), and a large body of cognitive psychology suggesting that individuals can be quite precise in evaluating choices on relatively coarse unidimensional supports, but display hardly any precision on finer supports. Specifically, for reasons explained below, we assume the cardinality of $\Pi$ to be equal to 5 and the cardinality of $\Lambda$ to be equal to 10 .

It is evident, however, that even for $|\Pi|=5$ and $|\Lambda|=10$, "brute force" elicitation for both candidates would require each responder to answer $5 \times 10 \times 2=100$ different questions on the subjective likelihood of each specific $(v, p)$ realization, an effort which would likely frustrate political experts, let alone regular voters. Garthwaite, Kadane, and O'Hagan (2005) present an insightful discussion on the difficulty of elicitation for multivariate priors. To this issue, the reader versed in elicitation may add the problem of effectively training telephone interviewers in the consistent elicitation of joint probabilities. ${ }^{5}$ Therefore, we follow an alternative route.

\subsubsection{Marginal Belief Distributions}

We first focus on information more easily elicitable from voters: the univariate marginals $f_{V}^{i, j}(v)$ and $f_{P}^{i, j}(p)$. Even in this case, full elicitation of marginals would require a large set of $(|\Pi|+|\Lambda|) \times 2=30$ questions. We streamline the process in order to maintain feasibility without excessive sacrifice of accuracy. We start by imposing a simple regularity assumption on the distribution of beliefs.

Assumption 2: Subjective belief distributions are unimodal.

Although restrictive, this assumption makes the interpretation of the elicited probabilities more direct. All of our remaining distributional assumptions can be illustrated using the questions in our surveys by way of example. We focus only on $A$ for brevity and consider first his ideological position $P$. We enquire about the central tendency of the marginal prior on ideology as follows.

Q1: How would you most likely define candidate $A$ 's political position?

Left (1); Center-Left (2); Center (3); Center-Right (4); Right (5); Don’t Know ( - 999).

\footnotetext{
${ }^{5}$ While the use of telephone interviews is not generally necessary, in our context it is was required to ensure timely elicitation of a large sample of the voting population as close as possible to election day.
} 
A reasonable interpretation of the answer, with minimal confusion for the respondent, is that the mode is elicited. In particular, we allow the mode, $\hat{p}$, to be only one of these five categories.

$$
\text { Assumption } 3: \Pi=\{1, \ldots, 5\} \text {. }
$$

An answer of "Don't Know/Don't Know $A$ " implies flat priors, or $f_{P}^{i, A}(p)=1 /|\Pi|=0.2$ for every $p$. Our choice of the set $\Pi$ follows the established result in cognitive psychology that individuals are well versed in choices over discrete sets of limited dimensionality $(|\Pi| \leq 10)$, but that this capacity deteriorates sharply when the number of options rises above small integers (Miller, 1956). Such an assumption, however, has costs, as emphasized in Manski and Molinari (2010).

Conditional on non-flat priors, we further enquire about the dispersion around the mode. ${ }^{6}$

Q2: How large is your margin of uncertainty around candidate A's political position?

Certain (1); Rather uncertain, leaning left (2); Very uncertain, leaning left (3);

Rather uncertain, leaning right (4); Very uncertain, leaning right (5).

We indicate the level of increasing tightness of the priors with $s \in \Sigma=\{1, \ldots, 4\}$, where $s=1$ is maximal dispersion, i.e., the case of flat priors; $s=2$ indicates substantial uncertainty (answers 3 or 5 to Q2); $s=3$ indicates intermediate uncertainty (answers 2 or 4 to Q2); and $s=4$ is maximal tightness, which coincides with a degenerate prior spiking at $\hat{p}$ (answer 1 to Q2). Q2 also elicits information about the skew of the beliefs. While we do not allow explicitly for an answer of symmetric dispersion for $s=2,3$, not to overload the responder, the estimation below allows for symmetric belief distributions. ${ }^{7}$ Let us indicate with $z \in\{-1 ; 1\}$ a negative (i.e., to the left/lower values) or positive (i.e., to the right/higher values) asymmetry in Q2.

Let us define the modal probability mass with $\phi_{P}=f_{P}^{i, A}(p=\hat{p})$. Intuitively, we assume the probability mass at the mode $f_{P}^{i, A}(p=\hat{p})$ is lower the higher the level of uncertainty. We allow $\phi_{P}$ to vary with $s$ and estimate $\phi_{P, s}$, from the data for $s=2,3$, imposing the bounds:

$$
\text { Assumption } 4: 1 /|\Pi| \leq \phi_{P, 2} \leq \phi_{P, 3} \leq 1 \text {. }
$$

We further assume the off-mode mass, $1-\phi_{P, s}$, to be allocated asymmetrically around the mode depending on the indicated asymmetry, z. We assume the off-mode mass decays proportionally

\footnotetext{
${ }^{6}$ Interviewers were trained during pilot interviews to explain to voters that this question entailed uncertainty about subjective evaluations on the candidates, and should not be interpreted as a right-or-wrong question.

${ }^{7}$ In our surveys, we actually included a possible answer "uncertain" to assess the share of respondents indicating symmetric dispersion around the mode. The share of respondents in that category was so low for ideology (and actually none for valence) that we omit it from exposition.
} 
to the distance $|p-\hat{p}|$ from the mode at a constant rate, as dictated by a function $g\left(x_{1}, x_{2}\right)$ : $\{1, \ldots,|\Pi|-1\} \times[0,1] \rightarrow[0,1]$ with $g_{x_{1}}\left(x_{1}, x_{2}\right) \geq 0$ and $g_{x_{2}}\left(x_{1}, x_{2}\right) \leq 0$. In synthesis, we impose:

$$
\text { Assumption 4' } f_{P}^{i, A}(p \neq \hat{p})=\left\{\begin{array}{cl}
1 /|\Pi| & \text { for } s=1 \\
g\left(\phi_{P, s}, z *(p-\hat{p})\right) & \text { for } s=2,3 \\
0 & \text { for } s=4 .
\end{array}\right.
$$

Concerning $g($.$) , we allocate \alpha_{P}\left(1-\phi_{P, s}\right)$ mass in the direction of the asymmetry imposing that $\alpha_{P} \in[1 / 2,1]$, and allocate $\left(1-\alpha_{P}\right)\left(1-\phi_{P, s}\right)$ in the opposite direction, assuming a linear decay of the off-mode mass in both directions. This specification of $g$ allows for a very flexible, but parametrically parsimonious marginal distribution.

Concerning the valence dimension $V$, we again enquire about the modal belief.

Q3: Setting aside his/her political position, how would you most likely grade candidate $A$ ?

From 1 (minimum competence) to 10 (maximum competence) or Don’t Know ( -999$)$.

The set $\Lambda$ is then assumed to be as follows:

$$
\text { Assumption } 5: \Lambda=\{1, \ldots, 10\} \text {. }
$$

This particular format of Q3 was driven by the familiarity of Italian voters with primary and secondary education grade scoring rules, with 10 indicating the best possible mark in a school assignment and failing grades being below 6 . The dispersion around the valence mode and the skewness of valence beliefs are modeled similarly to Assumptions 4 and 4' with $\Lambda$ replacing $\Pi$ in the construction of $f_{V}^{i, A}(v)$. We omit their description for brevity. For illustrative purposes, Figure 1 provides an example of the modeled prior beliefs about the valence of $A$ for one particular voter. The distribution in the figure is based upon the voter's reported mode $(\hat{p}=7)$ and uncertainty $(s=2)$ and the estimates we obtain for the parameters governing the distribution.

Finally, we must emphasize that we only elicit the beliefs about valence and ideology for the incumbent candidate, $A$, and his main challenger, $B$, due to the infeasibility of eliciting beliefs about all minor, third-party candidates participating in the election. In our estimation in Section 5, we assume that the beliefs of all non-incumbent candidates are the same as those elicited for the main challenger, $B$. While this is a stark assumption, we justify it by the fact that the main non-incumbent candidates were ideologically similar and their qualities were relatively unknown (flat beliefs along the valence dimension are quite common for non-incumbent candidates). ${ }^{8}$

\footnotetext{
${ }^{8}$ The main third-party challenger was also a right-wing candidate, like $B$, but was sidelined by their party due to pending legal litigation related to his previous stint in office. See Section 3 for more institutional details.
} 


\subsubsection{Joint Belief Distributions: A Copula-Based Approach}

Having derived the univariate marginals, we now derive the joint distributions for all voters. Given any two (univariate) marginals, it is possible to construct a joint (bivariate) distribution in infinite ways. Copulas, introduced by Sklar (1959), are useful devices for providing a representation of a multivariate distribution function in terms of its univariate marginal distributions.

Dropping the superscripts, given cumulative marginals, $F_{V}(v)=\operatorname{Pr}(V \leq v)$ and $F_{P}(p)=$ $\operatorname{Pr}(P \leq p)$, a copula function $C$ satisfies $F_{V, P}(v, p)=C\left(F_{V}(v), F_{P}(p)\right)$ where $F_{V, P}(v, p)=\operatorname{Pr}(V \leq$ $v, P \leq p)$ is the joint cumulative distribution function. $C$ is unique for continuous densities. For discrete densities, as in our setting, typically the same joint distribution can be represented by different copulas, but a specific copula uniquely identifies a joint distribution. The marginal distributions carry all of the information related to the scaling and shape of the joint distribution function, while the copula function incorporates the information concerning the dependence relationship among the random variables. For parsimony, we will focus on copula families characterized by one dependence parameter. Notice, however, that the dependence parameter does not coincide with a linear correlation parameter; nonlinear dependence is accommodated as well.

We investigate three popular types of copulas, allowing for different degrees of association $\rho$ between $V$ and $P$. First, independence between $V$ and $P$ produces the intuitive copula $F_{V, P}(v, p)=$ $F_{V}(v) * F_{P}(p)$. Second, we allow for common dependence across surveyed voters, given by association parameter $-1 \leq \rho \leq 1$, employing the Farlie-Gumbel-Morgensen (1960) family copula, $F_{V, P}(v, p)=$ $F_{P}(p) * F_{V}(v) *\left(1+\rho\left(1-F_{P}(p)\right) *\left(1-F_{V}(v)\right)\right)$, where $\rho>0$ implies positive dependence and $\rho<0$ negative dependence. Potentially, $\rho$ could be made voter-type dependent (e.g., allowing for a different $\rho$ for left and right-wing voters), but not voter-specific. The FGM family is flexible, but allows only small departures from independence. The third type of copula family we consider is the Frank family, $F_{V, P}(v, p)=1 / \xi * \log (1+D(\xi))$, with $D(\xi)=\left(e^{\xi F_{P}(p)}-1\right)\left(e^{\xi F_{V}(v)}-1\right) /\left(e^{\xi}-1\right)$ and $\rho=-\xi$. The Frank family allows larger departures from independence and requires $\rho \neq 0$. Indeed, the Frank copula is well suited to model outcomes with strong positive or negative dependence.

The dependence parameter $\rho$ is not elicited from the survey, but can be estimated from the data. Recall that we observe vote decisions and such decisions are function of the voters' posteriors. Given a copula family, we can estimate a dependence parameter $\rho$ as part of the vector of parameters, $\theta$, by maximizing the likelihood of observing those votes as in equation (1). One can further employ standard generalized likelihood ratio tests to assess the relative quality of the assumptions on the copula family and select the preferred family. We follow this approach. 
To summarize, our set of parameters of interest is $\theta=\left[\beta_{A}, \beta_{B}, \gamma, \zeta, \chi, \theta^{\prime}\right]$ with belief parameters $\theta^{\prime}=\left[\phi_{P, 2}, \phi_{V, 2}, \phi_{P, 3}, \phi_{V, 3}, \alpha_{P}, \alpha_{V}, \rho_{A}, \rho_{B}\right]$, where we allow the association parameter to be different for $A$ and $B$. Estimating $\theta^{\prime}$ from vote decisions is only feasible for the posterior joint distribution. The prior joint distribution can be fully characterized under an additional assumption.

\section{Assumption 6 : Subjective belief distributions have constant $\theta^{\prime}$.}

In particular, while we allow marginals to be affected by our informational treatment, we assume that the dependence between ideology and valence of the candidate is constant. For example, assuming that a moderate policy stance is positively correlated with smarter candidates, information that moves subjective priors toward higher levels of valence $V$ is allowed to have an impact on the policy stance $P$, pushing it toward a more moderate stance, but it is not allowed to change the association between $P$ and $V .^{9}$

Figure 2 and Figure 3 provide an example of the joint distributions for a particular voter's beliefs about candidate $A$ prior to the election campaign and after receiving the valence message treatment. Each joint distribution is determined assuming independence of the marginals and based on the estimates of the parameters governing the marginal distributions. For this particular voter, receiving the valence message increased his belief about the valence of $A$ and also reduced the uncertainty along both dimensions. In Section 6, we will see that such changes in beliefs are representative of voters receiving the valence message treatment.

\section{$3 \quad$ Experimental Design}

In May 2011, in collaboration with the reelection campaign of the incumbent mayor in the Italian city of Arezzo, we implemented the experimental strategy embedded in the above empirical model during the mayor's actual electoral campaign. Specifically, we divided the city into four areas, randomizing at the precinct level, and the incumbent sent different campaign messages both by mail and by phone call to voters in these areas. In this section, we describe the institutional setting, as well as the nature of the (randomized) campaign messages and tools.

\subsection{Institutional Setting}

In Italy, mayors of cities with more than 15,000 inhabitants are directly elected under a plurality system with runoff, that is, in the first round the candidate who obtains more than 50 percent of the

\footnotetext{
${ }^{9}$ As an alternative to Assumption 6, one could calibrate $\rho_{j}$ for the prior distribution at specific values and observe the sensitivity of the results. A natural range of values could be the confidence interval of the dependence parameter for the posteriors. We do not pursue this avenue here.
} 
votes is elected, otherwise the two candidates receiving the most votes compete in a second round which takes place two weeks later. Mayoral candidates are supported by one or more party lists, but voters can cast separate votes for a candidate and a party list supporting another candidate. They can also vote only for a mayoral candidate, without expressing any preference for party lists, but the opposite is not allowed, because valid votes for a party list are automatically attributed to the candidate for mayor supported by that party.

Elected mayors serve a five-year term and are subject to a two-term limit. Italian municipalities are in charge of a wide range of services, from water supply to waste management, from municipal police to certain infrastructures, and from housing to welfare policies. Mayors are the key political players at the local level, as they can also appoint the executive officers and dismiss them at will. The city council, which acts as the legislative body, can force the mayor to resign with a no confidence vote, but in this case the council is also dissolved. Because of this institutional setting, municipal elections have high salience and turnout is usually very high.

Arezzo is a provincial capital city in the center of Italy, located in the province of the same name. In 2011, it had 100,455 inhabitants and 77,386 eligible voters. For electoral purposes, the city is divided into 95 precincts (the smallest electoral unit which usually coincides with a cluster of streets), which vote in 42 polling places (e.g., schools, public buildings). From a political point of view, the city was contestable. Giuseppe Fanfani, the incumbent mayor elected in 2006 who accepted randomization of a part of his reelection campaign, belonged to the center-left coalition, but before his first election the center-right coalition won for two terms in a row. In 2011, his main challenger was the official candidate of the center-right coalition, Grazia Sestini, a former vice minister at the national level. Six other (minor) third-party candidates were also present in the ballot. The main third-party candidate was a former mayor of the center-right coalition, Luigi Lucherini, sidelined by his party due to pending legal trouble. ${ }^{10}$

Local political campaigns are not very sophisticated in Italy, and they mostly rely on public rallies, direct mailing, and TV appearances (but no ads). Phone banks are rarely used, and doorto-door canvassing almost never occurs.

\footnotetext{
${ }^{10}$ The mayor accepted our proposal to randomize his campaign because of the possibility of receiving potentially useful information. As the center-right coalition was split between a main challenger (Sestini) and a less competitive one (Lucherini), he expected either to win in the first round or to go to the runoff. Therefore, our randomized trial could provide him with an effective strategy for campaigning in the two weeks between the first and second round.
} 


\subsection{Randomized Campaign}

To operationalize our informational treatments, we studied the campaign materials of the incumbent and assembled relevant information so as to isolate slogans based on either his competence as city manager (valence message) or his political stance (ideology message). Because we wanted to stay away from the strategic game between him, the other candidates, and the voters (that is, we wanted to randomize his actual campaign), we actually devised two different ideological messages: one leaning toward the left and one leaning toward the center of the political spectrum. We then allowed him to choose between the two and he selected the leftist message.

Furthermore, although our treatment of interest coincides with partisan campaign messages delivered by one of the candidates, as opposed to non-partisan information, we wanted our informational treatments to be factual and non-emotional, as typical for cheap or costly signaling games. ${ }^{11}$ For this reason, we matched the main slogans with bullet points based on verifiable information about the incumbent's performance and policy choices during his first term in office. Future research should extend to emotional messages as well, but we did not explore this avenue here.

Appendix Figures A1 and A2 show the mail flyers containing the two messages. ${ }^{12}$ The valence flyer is built around two keywords: competence and effort. The implicit message is that voters should reelect the incumbent because he was competent and effective as city manager. The factual information provided refers to the fact that Arezzo developed an urban development plan that was ranked first by the regional government and received extra funding because of its quality. The extra funding was used to rebuild monuments, roads, and parking slots in the city center. The ideology flyer is built around two keywords: awareness and solidarity. The implicit message is that voters should reelect the incumbent because he shares values that are commonly associated with the Italian left. The bullet points further reinforce the leftist tone as they point to "public" services, such as childcare and food facilities for the poor, that were expanded during his first term in office. ${ }^{13}$ Notice that the two mail flyers are identical in size, layout, colors, fonts, number of words, and photo of the candidate; only the content of the campaign message differs.

\footnotetext{
${ }^{11}$ The marketing and advertising literature (see Liu and Stout, 1987) has explored subjective responses to factual versus emotional or nonfactual messages, indicating systematic differences. As an interesting counter, Gerber et al. (2011) present a randomized trial involving nonfactual campaign messages.

${ }^{12}$ In the Appendix, we also report the English translation of the text of the two flyers. Additional materials related to our randomized campaign can be found on the website: www.igier.unibocconi.it/randomized-campaign.

${ }^{13}$ To validate our operationalization of the two informational treatments ex ante, we randomly assigned the two flyers to 50 university students at Bocconi University (in Milan) who did not know the mayor of Arezzo. We then asked them to give their subjective assessment of the politician's valence and ideology using the same questions described in Section 2. For the 25 students who received the first message, the average valence evaluation was 6.650 (s.d. 0.963 ) and the average ideology evaluation was 3.100 (s.d. 0.700). For the 25 students who received the second message, these values were 5.450 (s.d. 0.973 ) and 2.050 (s.d. 0.669), respectively.
} 
The two campaign messages - valence and ideology — were supplied to voters in two ways, through direct mailing and phone calls. The randomization design was implemented as follows. We randomly divided the 95 precincts into four groups: (i) 24 precincts received the valence message; (ii) 24 precincts received the ideology message; (iii) 24 precincts received both messages; (iv) 23 precincts received no message (control group). Furthermore, we randomly split the first three groups into two subgroups: in the first, the treatment was administered by both direct mail and phone calls (12 precincts); in the second, by direct mail only (12 precincts). ${ }^{14}$

Appendix Table A1 reports the ex-ante balance tests of predetermined variables at the precinct level. The available variables include the number of eligible voters enlisted in each precinct, the city-wide neighborhood each precinct belongs to, and past electoral outcomes of national, regional, European, and municipal elections. As precincts were reshuffled in the last decade, some outcomes are not available for all 95 precincts. All of the predetermined variables are balanced across treatment groups. Only the number of eligible voters displays a coefficient significant at the 10 percent level, because of the presence of a few small precincts in the countryside that could not be spread across all groups. Removing these precincts from the analysis, however, does not alter the results.

In order to increase the effectiveness of the campaign messages, we drew useful insights from the U.S. experimental evidence summarized by Green and Gerber (2004). First, we acted in the week before election day, so as to ensure the message sticks in voters' minds. Second, we had our mail flyers designed by professionals and directly sent to individuals with their name and address on the envelope. ${ }^{15}$ Third, we did not use automated robo calls. We instead trained volunteers to make the campaign phone calls. Specifically, from the candidate's headquarters, volunteers called all selected households with the following protocol: first, they were instructed to talk with the voters and ask for their opinion for about two minutes. Then, they would ask the voter to listen to a recorded message from the candidate. At the end of the call, the recorded voice of the candidate read a 30 -second script with the above valence and ideology messages (or a combination of the two). ${ }^{16}$

Our randomized campaign used the above tools - mailers and phone calls - on a large scale. All households in the city received an envelope from the incumbent campaign. The envelope contained the official platform of the political parties supporting the candidate plus one of our flyers (or both of them) according to the assigned treatment group. Voters in the control group received just the

\footnotetext{
${ }^{14}$ As we were already pushing the boundaries in terms of sample size, we decided that the accuracy loss could not justify an additional subgroup treated by phone calls only.

${ }^{15}$ To avoid sending multiple envelopes to the same household, we randomized the name of the receiver within each household, because we did not want to target only household heads.

${ }^{16}$ In the Appendix, we report the English translation of the text of the three recorded messages. Original audio files are available on the website: www.igier.unibocconi.it/randomized-campaign.
} 
platform, but not the flyer with our informational treatment. This procedure allowed us to keep the candidate unaware of the randomization outcome. Of course, the candidate approved all messages and paid for the costs of the campaign, but we gave him closed envelopes so that he could not infer which precincts were receiving one flyer as opposed to the other. In summary, all households with at least one member enlisted as an eligible voter received our mailers. On top of this, about 25 percent of the households in the treatment groups also received a campaign phone call. ${ }^{17}$

\subsection{Data}

To elicit beliefs about the valence and ideology of the two main candidates along the lines described in Section 2, we ran two surveys of 2,042 eligible voters distributed across all treatment groups. We ran the first survey ten days before the election and, most importantly, before voters received the informational treatments, so as to measure priors and demographic characteristics. The second survey was conducted the day after the election and was meant to measure posteriors and (selfdeclared) vote choices. To implement our surveys, we contracted a company from another Italian region, so as to have interviewers with different accents from the campaign volunteers and to remove any link between the campaign and the survey phone calls. About 71 percent of the respondents in the first survey also replied to the question about whether they voted or not in the second survey. Therefore, our sample is made up of 1,455 voters, 1,306 of whom actually voted for one of the candidates. However, 231 of the 1,306 voters did not specify for which candidate they voted and for this reason we accommodate for potentially non-random non-responses in the model estimation.

To further validate our randomization design ex post, we checked for balancing of the characteristics of voters across treatment groups. Survey variables include demographic characteristics, educational attainment, political orientation, home ownership, and how often voters read newspapers or watch TV. The results are reported in Appendix Table A2. None of these (self-declared) individual characteristics is statistically different across treatment groups. ${ }^{18}$

Table 1 summarizes election results at the precinct level. The incumbent mayor won his bid for reelection with a vote share 51.3 percent, enough to avoid a run off. Table 2 shows the (self-

\footnotetext{
${ }^{17}$ Because of budget and time constraints, we could not reach all households by phone.

${ }^{18}$ As an additional ex-post validation of the randomization design, we built proxies of Census characteristics at the precinct level. This exercise has two limitations, however. First, data from the last available Census refer to 2001. Second, precincts are not easily matchable with Census cells. To overcome the second limitation, we implemented the following geocoding procedure: 1) for each street (i.e., line) belonging to a precinct we calculated the weighted average of the characteristics of the Census cells (i.e., polygons) overlapping with that street (with weights equal to the overlapping segments); 2) for each precinct, we calculated the weighted average of the characteristics of the associated streets (with weights equal to the population living in each street). Appendix Table A3 reports the balancing tests of these Census characteristics across treatment groups. Although the estimates are likely to suffer from attenuation bias due to measurement error, none of them is statistically different from zero.
} 
declared) vote choices of surveyed individuals. As often happens in post-electoral polls, there is a slight bandwagon effect in vote declarations favoring the winning candidate (57.1 percent). The bandwagon is not a concern for estimation under the (plausible) assumption that this effect is orthogonal to our treatment groups. In any case, recall that a strength of our approach is that we can cross-validate the consistency of treatment effects in the survey data (at the individual level) with those in the aggregate actual voting data (at the precinct level).

\section{Evidence on Choices}

In this section, we evaluate whether our informational treatments had any effect on voting choices at both the precinct and individual level. Based on the experimental design described in the previous section, the (reduced-form) causal effects of campaigning on valence versus ideology can be estimated through the OLS model:

$$
Y_{i}=\sum_{k=1}^{6} \gamma_{k} D_{i}^{k}+\eta_{i}
$$

where $Y_{i}$ is the electoral outcome of interest, $D_{i}^{k}$ are binary indicators capturing treatment group status, and $\eta_{i}$ is the error term. ${ }^{19}$ The six treatment groups, $D^{k}$, include: valence message by phone (and mail); valence message by mail only; ideology message by phone (and mail); ideology message by mail only; double message by phone (and mail); and double message by mail only. Observations receiving no informational treatment are the excluded reference group.

Table 3 summarizes the results in the aggregate sample, whose units of observation are the 95 electoral precincts. At the margin, partisan ads have no impact on turnout. There is evidence, however, that campaigning on valence brings more votes to the incumbent when phone calls are used as a campaign tool. Phone calls delivering the valence message increase the incumbent's vote share by 4.1 percentage points (i.e., by about 8.4 percent with respect to the average share in the control group). This estimated effect is sizable, because it must be interpreted as an intention-totreat effect: in fact, only 25 percent of the households in the treated precincts received a campaign phone call and not all of them accepted our invitation to listen to the message recorded by the candidate. Because of the small sample size, however, coefficients are not precisely estimated and we cannot reject the null hypothesis that they are statistically equal to each other.

\footnotetext{
${ }^{19}$ To account for potential intra-class correlation between neighboring precincts we cluster standard errors at the polling place level, while to account for correlated time shocks in survey data we include fixed effects for the interview date; results are not sensitive to these modeling choices. Empirical results are qualitatively similar when we include predetermined variables as additional covariates, although the specification becomes demanding in terms of degrees of freedom in the aggregate data (results available upon request).
} 
What we can reject in the aggregate data is the null that the two campaign tools - mailers versus phone banks - are equally effective. If we merge together all groups that received an informational treatment with the same campaign tool, we find that-with respect to the control group-phone calls increase the incumbent vote share by 2.7 percentage points (p-value: 0.019), while, statistically, the effect of mailers is both different from 2.7 and not different from zero. This result is in line with U.S. experimental evidence showing that mailers are usually ineffective in political campaigns (see Green and Gerber, 2004). In our case, however, mailers are also administered to voters who receive a phone call. Therefore, we cannot rule out the possibility that mailers alone are ineffective, but they become effective when interacted with other campaign tools delivering the same message.

Based on the above evidence on the ineffectiveness of mailers alone, Table 4 estimates equation (3) imposing this restriction: including both "mail" and "no message" in the control group. Standard errors are slightly lower, and the point estimates and the statistical significance of the included regressors are almost identical with respect to the full model.

In order to validate the aggregate evidence and to gain statistical accuracy, we estimate equation (3) using the individual-level survey data, where sample size is less of an issue. The units of observation are the 1,455 eligible voters for turnout or the 1,306 actual voters for the vote shares. As all outcomes are binary, estimation is by probit. The price we pay is that here outcomes are selfreported, that is, based on vote declarations and not on actual choices. The underlying assumption is that self-reporting bias is the same across treatment groups. ${ }^{20}$ Table 5 reports the estimates for all treatment groups. Results are consistent with the aggregate evidence. Phone calls delivering the valence message increase the incumbent's vote share by 9.5 percentage points (i.e., by about 16 percent with respect to the control group). This effect is larger than in the aggregate data, but treatment intensity is also higher in this context, because all surveyed households received the campaign phone call, as opposed to only 25 percent in the aggregate data. Phone calls are still the more effective campaign tool, with a difference significant at the 1 percent level. More importantly, conditional on campaign tool, the valence message is now statistically more effective than the ideology message at the 10 percent level. ${ }^{21}$ Table 6 further emphasizes this point by

\footnotetext{
${ }^{20}$ As we document in the next section, non-response in vote declarations is likely to be non-random, i.e., to be associated with individual characteristics such as ideology or prior beliefs. This does not imply, however, that (nonrandom) non-response should not be orthogonal to (random) treatment assignment.

${ }^{21}$ Although our experimental design — based on randomization at the precinct level — did not allow for stratification on individual characteristics, we nonetheless investigated potentially heterogeneous responses by repeating the baseline estimation in split samples along many observable dimensions. The positive impact of valence phone calls on the incumbent's vote share turns out to be statistically larger for females, individuals older than 65 years, individuals without a college degree, and less-informed voters. Instead, there is no significant heterogeneity along previous political orientation, home ownership, or type of occupation (results available upon request).
} 
focusing on informational treatments administered by phone: campaigning on valence brings more votes to the incumbent and to the party lists that support him, and these point estimates are statistically larger than those of campaigning on ideology alone.

Finally, in Appendix Table A4, we evaluate the potential impact of spillovers across neighboring precincts. As a counterpart to Table 5, we estimate the effects on voting choices of the average treatment intensity for individuals voting in the same polling place, although they may belong to different precincts and therefore treatment groups. If Assumption 1 (SUTVA) is met, we expect these measures to have no impact on choices for treatments detected as ineffective in Table 5, and to have a less significant impact for treatments detected as effective in Table 5 . It is thus reassuring that none of these spillover estimates is statistically different from zero. ${ }^{22}$

\section{$5 \quad$ Model Estimation}

We now report the results from the maximum likelihood (ML) estimation of our voting model. The estimation procedure is straightforward and relies on fitting individual vote declarations, whichin Section 4 -we have shown to closely match actual vote outcomes. ${ }^{23}$ The specification selection warrants some discussion, however.

Section 2 discussed non-response parameters $\left[\beta_{A}, \beta_{B}\right]$, preference parameters $[\gamma, \zeta, \chi]$, belief parameters $\left[\phi_{P, 2}, \phi_{V, 2}, \phi_{P, 3}, \phi_{V, 3}, \alpha_{P}, \alpha_{V}, \rho_{A}, \rho_{B}\right]$, and the choice of a copula family [Independent; Frank; FGM]. Concerning the preference parameters, a large literature in political economics and political science has emphasized preference heterogeneity, for instance in the case of distaste for specific policy outcomes, such as inflation or unemployment. ${ }^{24}$ We can easily accommodate this feature by allowing a different $[\gamma, \zeta, \chi]$ vector for left-wing $(\mathrm{L})$, centrist $(\mathrm{C})$, and right-wing $(\mathrm{R})$ voters. We can as well accommodate heterogeneity in the dependence structure of the beliefs $\left[\rho_{A}, \rho_{B}\right]$ by allowing them to differ for L, C, and R voters. Concerning the skewness of the marginal beliefs, one can experiment with relaxing the simple $\left[\alpha_{P}, \alpha_{V}\right]$ to a more flexible $\left[\alpha_{P, 2}, \alpha_{V, 2}, \alpha_{P, 3}, \alpha_{V, 3}\right]$, thus

\footnotetext{
${ }^{22}$ Notice that point estimates are not directly comparable with those in Table 5 because the regressors are no longer dummies but shares. Compared to the average values and standard deviations of the spillover shares, however, point estimates are generally small, and - as expected - they are larger for the administration of the valence message by phone, because in those cases the shares also include treated voters for whom there exists a non-zero effect.

${ }^{23}$ The identification of the model is assessed through several rounds of Monte Carlo simulations. For given parameter values we simulated individual votes and ensured that the estimation based on the simulated data converged to the original structural values. Our likelihood function depends on a relatively small number of parameters. This allows for a fairly extensive search for global optima over the parametric space. We use the patternsearch algorithm of Matlab with differing initial values. Repeating the optimization procedure consistently delivers identical global optima. We also employed a genetic algorithm (GA) global optimizer with a large initial population of 10,000 values followed by a simplex search method using the GA values as initial values for the local optimizer. Both methods resulted in the same estimates but the patternsearch algorithm converges faster in our environment.

${ }^{24}$ Among others, see Di Tella, MacCulloch, and Oswald (2001); Gerber and Lewis (2004).
} 
allowing the extent of the skew to change with the variance. All these are testable parametric constraints that can be assessed based on likelihood ratio tests. On the other hand, the choice of the copula family requires a generalized likelihood ratio test approach, as the copula families we consider are non-nested. The Vuong (1989) model selection test is appropriate for this purpose.

In Appendix Tables A5 and A6 we report the full set of model estimates for all the relevant combinations of parametric and copula assumptions, which are pairwise tested in Appendix Tables A7, A8, and A9 through likelihood ratio tests and Vuong tests (for the copula). According to the tests, the preferred specification allows for heterogeneity in preference parameters along the voter's self-declared ideological stance, for independence between the ideological and valence dimensions of both candidates, and for common $\left[\alpha_{P}, \alpha_{V}\right]$. Thus, the preferred model specification estimates $\theta=\left[\beta_{A}, \beta_{B},\left\{\gamma^{z}, \zeta^{z}, \chi^{z}\right\}_{z=L, C, R}, \phi_{P, 2}, \phi_{V, 2}, \phi_{P, 3}, \phi_{V, 3}, \alpha_{P}, \alpha_{V}\right]$. We report the ML estimates for this model in Table 7.

We first note that the estimates of the probability of response (i.e., the probability of disclosing one's vote) are 0.76 and 0.99 for predicted votes for $A\left(\beta_{A}\right)$ and $B\left(\beta_{B}\right)$, respectively, and are very precisely estimated. While we cannot reject the null that the probability of response is one for voters that voted for $B$, we can strongly reject the null for voters that voted for $A$, which justifies our choice of modeling non-random non-response. ${ }^{25}$ Interestingly, voters who are predicted to have voted $B$ are more likely to disclose their vote, contrary to the possible hypothesis that those who voted for the winner $(A)$ should be more willing to disclose their preference for the winner. This result squares with the intuition of conservative voters in Tuscany being particularly assertive.

Generally, the preference parameters are estimated with precision. The parameter governing the interaction between valence and ideology values for the voter, $\chi$, is estimated to be a fairly precise zero. Imposing $\chi=0$ clarifies the interpretation of $\gamma$ as the relative weight in preferences of valence $\left(x^{\prime}\right)$ to the weight of ideology $\left(1-x^{\prime}\right)$. Hence, $\gamma=\frac{x^{\prime}}{1-x^{\prime}}=1$ implies equal weights along both dimensions and this is what we find for $\mathrm{L}$ and $\mathrm{C}$ voters. The weight on valence for $\mathrm{R}$ voters is, however, much lower, around 27 percent, versus a 73 percent weight on ideology.

Concerning the curvature of the ideological loss function $u($.$) , surprisingly, we find \zeta<1$ for all three types of voters, indicating increasing losses but at diminishing rates from policies further away from the voter's bliss point. This is in contrast with the standard assumption of $\zeta=2$, quadratic

\footnotetext{
${ }^{25}$ As further evidence in support of the probability of disclosing one's vote being non-random, we ran a probit regression of a dummy indicating whether or not a vote was disclosed on the elicited posterior beliefs and voter's ideology. An $\mathrm{F}$ test strongly rejects the null hypothesis of no explanatory power and hence random non-response ( $\mathrm{p}$-value $=0.000)$. Interestingly, the stronger voters' beliefs about the valence of either candidate, the more likely voters are to disclose their vote.
} 
losses, for example. For centrist voters, $\zeta$ is actually estimated to be zero, although the estimate is rather imprecise. With $\zeta=0$, the loss due to deviations from the voter's bliss point is constant and independent of the candidate's policy.

The belief parameters are also precisely estimated for the most part. Interestingly, the specification feeds back information which allows us to assess certain features of the survey design. The model clearly captures an intermediate level of uncertainty between flat $(s=1)$ and degenerate priors $(s=4)$ for both valence and ideology. The on-the-mode probability mass, $\phi_{V, 3}$, is estimated at around 0.40 for valence and the corresponding parameter for ideology, $\phi_{P, 3}$, is estimated at around 0.58. Hence, voters answering 2 to 5 to Q2 are more certain than having flat priors, but definitely not sure about the candidate being at the mode (i.e., answer 1 to Q2). Along the valence dimension, voters do not perceive the distinction between "very uncertain" $(s=2)$ and "rather uncertain" $(s=3)$ given that, at the estimated values, $\phi_{V, 3}=\phi_{V, 2}$. However, along the ideology dimension, "rather uncertain" does result in less dispersion in the marginal distribution. In addition, the answers given to the skewness dimension seem to be important only along the ideological dimension, where $\alpha_{P}>1 / 2$, but not on the valence dimension where $\alpha_{V}$ is not significantly different from $1 / 2$, indicating a symmetric partitioning of the off-mode probability mass.

Finally, concerning the choice of the copula and the estimates of the dependence parameters, we note that, although both the FGM and Frank copula models have typically higher likelihood values than under independence, the loss of parsimony of the model does not justify the additional parameters according to the Vuong tests (see Appendix Table A9). This result occurs because we can only estimate $\left[\rho_{A}, \rho_{B}\right]$ very imprecisely, which can be easily rationalized. The parameters $\left[\rho_{A}, \rho_{B}\right]$ are essentially identified by voters that are: i) close to a change in their vote choice between $A$ and $B$; and ii) characterized by non-degenerate and non-flat beliefs along both the ideology and valence dimensions. These joint restrictions substantially reduce the number of observations providing useful identifying variation for estimating $\left[\rho_{A}, \rho_{B}\right]$. Notwithstanding the lack of precision, looking at the signs of the estimated dependence parameters in Appendix Tables A5 and A6 is intriguing. We generally find evidence of a positive association between left position and valence perceptions for $A$ driven by left-wing voters, and a positive association between right position and valence perceptions for $B$ driven by right-wing voters. More extreme positions appear to be correlated with higher valence, in accordance with the theoretical results in Bernhardt et al. (2011). The Frank copula is preferred over the FGM copula, although we cannot reject the null of equal fit.

The structural estimation has allowed us to fully recover all of the parameters necessary to characterize the individual belief distributions. We proceed to the analysis of voters' beliefs next. 


\section{Evidence on Beliefs}

The effect of partisan ads on beliefs is interesting per se, and it can shed light on the robustness of the impact of the same ads on voting choices, based on their mutual consistency. To increase accuracy, we restrict our attention to informational treatments delivered by phone, that is, by means of the effective campaign tool. In Tables 8 and 10, the outcomes are the average and the standard deviation of the individual belief distributions - from model estimation - of both valence and ideology of the incumbent and of the opponent, respectively. In Tables 9 and 11, we look at the same moments of the individual belief distributions, but we instead use survey responses as opposed to estimates from the structural model. Specifically, the outcomes are the (self-reported) mode and a binary measure of "uncertainty" (namely, a dummy capturing flat priors in survey responses). Estimation is by OLS for multivalued or continuous outcomes and by probit for binary outcomes. ${ }^{26}$

For the incumbent, both the valence and ideology messages have the expected direct effects. Information on valence increases perceived competence by about 5 percent with respect to the average perception. The same holds for information on ideology, as perceived ideology decreases (i.e., moves to the left) by about 5 percent. Interestingly, second moments are also affected by the two treatments: uncertainty about the incumbent's valence or ideology is reduced by additional campaign information along the corresponding dimension. Decreased uncertainty is a relevant channel of the effect of campaign information on choices. As a matter of fact, the positive effect of valence phone calls on the incumbent's vote share is stronger in the subsample of voters whose priors are flat. In the treated group, we observe a sharp tightening of the belief distribution, which contributes to the overall effect.

The negative impact of ideology message phone calls on the candidate's ideology does not translate into more (or less) votes for $A$. Notwithstanding the large utility weight voters place on this dimension, the shift in the belief distributions caused by the ideology phone calls is not strong enough to affect voting choices. ${ }^{27}$

With respect to ideology, information on the incumbent's position has interesting cross-effects on the perception of the opponent's position. Voters who received the ideology phone call from the incumbent campaign move their subjective evaluation of the opponent $B$ to the right by 3 percent. The treatment also reduces uncertainty along this dimension. This might be due to the increased

\footnotetext{
${ }^{26}$ For the sake of intuition, we use OLS also for the ideology mode, which can only take five (ordinal) values. Results from ordered Probit are qualitatively identical (available upon request).

${ }^{27}$ An alternative explanation might be that the ideology message affects right-wing and left-wing in the opposite way, but this is not what we find in our sample. Ideology phone calls had negligible effects on voting behavior for both types of voters, while their impact on beliefs was almost equivalent.
} 
salience of the left/right distinction or to its relative nature, and it is causal evidence of crosslearning between political campaigns. This finding is consistent with a sophisticated subjective updating behavior on the part of the voters. For example, this type of evidence would be consistent (albeit not proof of) Bayesian updating in a two-candidate signaling game.

\section{Model Fit and Counterfactual Electoral Campaigns}

To conclude our analysis we discuss model fit results and counterfactual electoral simulations based on our structural estimates. Overall, the structural model under the baseline specification predicts the actual vote correctly 88.7 percent of the time. In particular, we predict correctly 95.9 percent of the votes for candidate $A$ and 70.7 percent of the votes for $B$. Here, the sample under consideration is restricted to the voters who disclosed their vote only, since we do not know the actual vote of those who chose not to disclose it.

Turning to counterfactuals, no standard protocol exists in the literature for running these types

of exercises, so we have devised one. Suppose one wishes to assess what would have happened to the aggregate vote share of $A$ if everybody in the city had received the valence message (i.e., had gotten treatment $H=1$ ). We simulate this counterfactual campaign using a five step procedure.

Under our stability Assumption 6, for each voter $i$, it is possible to generate prior belief distributions about $A$ and $B$ based upon their prior survey answers and $\theta^{\prime}$, the structural parameter vector estimated from votes and posterior beliefs. This is the first step. Secondly, for each voter $i \in \mathcal{T}(h)$ with $h \neq 1$ (i.e., not treated with the valence message to begin with), it is always possible to find the nearest neighbor treated match in the group $h=1, i^{\prime} \in \mathcal{T}(1)$, based on the Mahalanobis distance metric derived from covariates (such as age, gender, marital status, education, priors, and ideology). Voter $i^{\prime}$ is the closest match to voter $i$ for which the causal effect of valence on beliefs is actually observed. Essentially, this is the same intuition one would follow in propensity score estimation. Once the closest match $i^{\prime}$ has been identified, as third step we compute the difference between $i$ 's marginal posterior and prior beliefs at every point of the support of each of the valence and ideology dimensions. Fourth, we apply $i$ 's pointwise changes in beliefs to $i$ 's priors to calculate the counterfactual posterior marginal beliefs of $i$, under the assumption that, had $i$ gotten the same treatment as $i^{\prime}$, she would have updated her beliefs in the same way as $i^{\prime}$. Fifth, we compute joint posterior beliefs using the appropriate copula family and the estimated $\rho$ 's. Given the posteriors for each voter $i$, we obtain a simulated electoral outcome, by calculating the expected utility of each candidate for $i$ and then predicting their vote for the candidate with the highest expected utility. 
Importantly, this simulation procedure does not require the simulated electoral campaign to only focus on a single treatment, but it can be tweaked to targeting specific subgroups with different treatments. For instance, we can simulate a campaign in which valence messages are sent to known centrist and right-wing voters while ideological messages are sent to left-wing voters. This is of particular relevance at a point in time when political campaigns, especially in the US, have increasingly turned to specialized companies, such as Aristotle, for micro data acquisition and selective campaign advertising, a trend well under way also in commercial and online marketing.

We explore some of the possible electoral counterfactuals in Table 12. For each counterfactual, we include all voters, even those who did not disclose their actual vote. Table 12 reports counterfactual electoral outcomes for five types of campaigns by $A$ : (1) a blanket valence campaign; (2) a blanket ideological campaign; (3) a blanket double valence-ideology campaign; (4) a targeted campaign of valence messages to center and right-wing voters and double messages to left-wing voters; (5) a targeted campaign of ideological messages to center and right-wing voters and double messages to left-wing voters. All results are benchmarked to the simulated electoral outcome that would have realized in the absence of any campaign message on our part. The counterfactuals are also assessed in their precision by constructing 95 percent asymptotic confidence intervals based on bootstrapping from the asymptotic distribution of the parameters. All our counterfactual estimates appear statistically precise.

The most effective possible campaign is the electoral campaign in which valence messages alone are sent to all voters. A blanket valence campaign increases the vote share of $A$ by 2.2 percentage points relative to no campaign, which is more than enough to make the difference in a closelycontested election. Interestingly, a blanket campaign of ideology messages actually reduces the vote share of $A$ substantially, in fact by the same 2.2 percentage points that a blanket valence campaign would instead bring to $A$. In fact, the 95 percent confidence intervals for the two simulated campaigns do not overlap, so we can be reasonably certain that a blanket valence campaign would have outperformed a blanket ideology campaign. To understand why the ideology campaign reduces vote shares, recall that the ideological message in our experiment has a leftist bent, reducing the expected utility from $A$ for $R, C$ and possibly the most moderate of the $L$ voters. Overall, the loss of support from $C$ and $R$ in our sample turns out to more than sufficient to offset the gain in $L$ voters. For the same reason, a double campaign of both ideology and valence messages increases the vote share of $A$ by 0.5 percentage points, which, while effective, is not as effective as the blanket valence-only campaign. Finally, the mixed campaign in which $L$ voters get both types of messages while $C$ and $R$ voters get valence messages only is almost as effective as the valence campaign, 
while the campaign in which $L$ voters get both types of messages while $C$ and $R$ voters get ideology messages substantially decreases $A$ 's vote share. In summary, consistently with our overall results, campaigning on valence appeared the most effective tool to persuade voters.

\section{Conclusion}

This paper presents novel evidence on the effects of campaign information on voters' decisions in a large-scale field experiment. Importantly, our effects are observed both in vote declarations of surveyed voters and in actual vote outcomes at the precinct level. To the best of our knowledge, this is the first empirical randomization exercise in the literature that operates at the scale of an entire election and covers the entire voting population in a mature democracy. Both our reduced-form and structural estimation results uncover large electoral gains from valence-based informational campaigning, possibly due to the relatively higher lack of prior information about the candidates along this dimension.

An additional contribution of our paper is to present a belief elicitation protocol that allows us, when combined with information on the electoral choices of voters, to completely characterize voters' beliefs about candidates along both the ideological and valence dimensions. Our methodology allows us to flexibly incorporate multivariate belief distributions within a structural random utility voting model. We then employ this empirical model to structurally estimate both belief distributions and voters' preference parameters.

From a methodological viewpoint, we incorporate a general structure of beliefs updating that goes well beyond what normally achievable with standard assumptions in the political and commercial advertising literature. For instance, let us consider conjugate priors of the Gaussian family. With normal beliefs new signals cannot reduce the precision of the subjective distributions, they always reduce the variance of these distributions. But relying on such beliefs is very restrictive. To see this consider another intuitive belief distribution: a binomial. When there are two (or more generally finite) states, the probability of the "good" state can go up or down depending on the signal value. As a result, the variance of the beliefs can actually increase or decrease after receiving additional information. Hence, the importance of leaving the beliefs family unrestricted is crucial in not forcing erroneous assumptions onto the data.

Our estimates show that the utility weight placed by voters on a candidate's policy position is of approximately equal magnitude to that placed on a candidate's valence and that the common assumption of convexity of the losses from ideological distance is not supported by the data. We 
also show how the informational treatments we designed systematically influence both the first and second moments of voters' marginal beliefs about both candidates in the electoral race, not only the beliefs about the candidate originating the message. We believe this causal evidence of cross-campaign learning can prove useful for understanding the level of sophistication in subjective updating by voters.

Potential applications of our elicitation methodology and estimation appear to be quite wide, including, in addition to political campaigning, commercial advertising and marketing. Our approach could be of use for the assessment of any type of informational treatment for randomized controlled trials, most of them currently performed in developing countries. Finally, our incorporation of the probability of non-response may be applied in many other contexts in which non-random nonresponse to survey questions seems plausible (e.g., reports of income or other labor-related questions for which those surveyed may be uncomfortable disclosing information). 


\section{References}

[1] Ansolabehere, Stephen, and Shanto Iyengar. 1995. Going Negative: How Political Advertisements Shrink and Polarize the Electorate. New York: The Free Press.

[2] Ansolabehere, Stephen, Shanto Iyengar, Adam Simon, and Nicholas Valentino. 1994. "Does Attack Advertising Demobilize the Electorate?" American Political Science Review, 88, 829838.

[3] Ansolabehere, Stephen and James M. Snyder. 2000. "Valence Politics and Equilibrium in Spatial Election Models," Public Choice, 103, 327-336.

[4] Ansolabehere, Stephen, James M. Snyder, and Charles Stewart, III. 2001. "Candidate Positioning in U.S. House Elections," American Journal of Political Science, 45, 136-159.

[5] Aragones, Enriqueta and Thomas R. Palfrey. 2002. "Mixed Equilibrium in a Downsian Model with a Favored Candidate," Journal of Economic Theory, 103, 131-161.

[6] Ashworth, Scott and Ethan Bueno de Mesquita. 2009. "Elections with Platform and Valence Competition," Games and Economic Behavior, 67, 191-216.

[7] Banerjee, Abhijit, Selvan Kumar, Rohini Pande, and Felix Su. 2011. "Do Informed Voters Make Better Choices? Experimental Evidence from Urban India," MIT manuscript.

[8] Banerjee, Abhijit, Donald Green, and Rohini Pande. 2012. "Can Voters be Primed to Choose Better Legislators? Evidence from Voter Campaigns in India," MIT manuscript.

[9] Bernhardt, Dan, Odilon Camara, and Francesco Squintani. 2011. "Competence and Ideology," Review of Economic Studies, 78, 487-522.

[10] Blass, Asher A., Saul Lach, and Charles F. Manski. 2010. "Using Elicited Choice Probabilities to Estimate Random Utility Models: Preferences for Electricity Reliability," International Economic Review, 51, 421-440.

[11] Chappell, Henry W. Jr. 1994. "Campaign Advertising and Political Ambiguity," Public Choice, 79, 281-303.

[12] Cox, David R. 1958. Planning of Experiments. New York: Wiley.

[13] Dewan, Torun, Macartan Humphreys, and Daniel Rubenson. 2010. "The Impact of Leaders and the Messages They Convey," LSE manuscript.

[14] Di Tella, Rafael, Robert J. MacCulloch, and Andrew J. Oswald. 2001. "Preferences over Inflation and Unemployment: Evidence from Surveys of Happiness," American Economic Review, 91, 335-341.

[15] Dominitz, Jeff and Charles Manski. 1996. "Eliciting Student Expectations of the Returns to Schooling," Journal of Human Resources, 31, 1-26.

[16] Duffy, John and Margit Tavits. 2008. "Beliefs and Voting Decisions: A Test of the Pivotal Voter Model," American Journal of Political Science, 52, 603-618. 
[17] Enelow, James M. and Melvin J. Hinich. 1982. "Nonspatial Candidate Characteristics and Electoral Competition," Journal of Politics, 44, 115-130.

[18] Farlie, Dennis J. 1960. "The Performance of Some Correlation Coefficients for a General Bivariate Distribution," Biometrika 47, 307-323.

[19] Fujiwara, Thomas and Leonard Wantchekon. 2013. "Can Informed Public Deliberation Overcome Clientelism? Experimental Evidence from Benin," American Economic Journal: Applied Economics, forthcoming.

[20] Galasso, Vincenzo and Tommaso Nannicini. 2011. "Competing on Good Politicians," American Political Science Review, 105, 79-99.

[21] Garthwaite, Paul H., Joseph B. Kadane, and Anthony O'Hagan. 2005. "Statistical Methods for Eliciting Probability Distributions," Journal of the American Statistical Association, 100, 680-700.

[22] Gerber, Alan S., James G. Gimpel, Donald P. Green, and Daron Shaw. 2011. "How Large and Long-lasting Are the Persuasive Effects of Televised Campaign Ads? Results from a Randomized Field Experiment," American Political Science Review, 105, 135-150.

[23] Gerber, Alan S., and Donald P. Green. 2000. "The Effects of Canvassing, Telephone Calls, and Direct Mail on Voter Turnout: A Field Experiment," American Political Science Review, 94, $653-63$.

[24] Gerber, Alan S., Donald P. Green, and Ron Shachar. 2003. "Voting May Be Habit-Forming: Evidence from a Randomized Field Experiment," American Journal of Political Science, 47, $540-50$.

[25] Gerber Elisabeth R. and Jeffrey B. Lewis. 2004. "Beyond the Median: Voter Preferences, District Heterogeneity, and Political Representation," Journal of Political Economy, 112, 13641383.

[26] Gill, Jeff and Lee D. Walker. 2005. "Elicited Priors for Bayesian Model Specifications in Political Science Research," Journal of Politics, 67, 841-872.

[27] Green, Donald P., and Alan S. Gerber. 2004. Get Out the Vote: How to Increase Voter Turnout. Washington, D.C.: Brookings Institution Press.

[28] Groseclose, Timothy. 2001. "A Model of Candidate Location When One Candidate Has a Valence Advantage," American Journal of Political Science, 45, 862-886.

[29] Kadane, Joseph and Lara J. Wolfson. 1998. "Experiences in Elicitation," Journal of the Royal Statistical Society, 47, 3-19.

[30] Kartik, Navin and R. Preston McAfee. 2007. "Signaling Character in Electoral Competition," American Economic Review, 97, 852-870.

[31] Lee, David, Enrico Moretti and Matthew J. Butler. 2004. "Do Voters Affect or Elect Policies? Evidence from the U.S. House," Quarterly Journal of Economics, 119, 807-859.

[32] Liu, Scott and Patricia Stout. 1987. "Effects of Message Modality and Appeal on Advertising Acceptance," Psychology and Marketing, 4, 167-87. 
[33] Manski, Charles F. 2004 "Measuring Expectations," Econometrica, 72, 1329-1376.

[34] Manski,Charles F. and Francesca Molinari. 2010. "Rounding Probabilistic Expectations in Surveys," Journal of Business and Economic Statistics, 28, 219-231.

[35] Miller, George A. 1956. "The Magical Number Seven, Plus or Minus Two: Some Limits on Our Capacity for Processing Information," Psychological Review 63, 81-97.

[36] Nickerson, David W. 2008. "Is Voting Contagious? Evidence from Two Field Experiments," American Political Science Review, 102, 49-57.

[37] Ramalho, Esmeralda A. and Richard J. Smith. 2012. "Discrete Choice Nonresponse," Review of Economic Studies, 7, 34-58.

[38] Rubin, Donald B. 1978. "Bayesian Inference for Causal Effects: The Role of Randomization," The Annals of Statistics, 79, 1-20.

[39] Savage, Leonard. 1971. "Elicitation of Personal Probabilities and Expectations," Journal of the American Statistical Association, 66, 783-801.

[40] Schofield, Norman. 2003. "Valence Competition in the Spatial Stochastic Model," Journal of Theoretical Politics, 15, 371-383.

[41] Sklar Abe. 1959. "Fonctions de rï $\frac{1}{2}$ partition $\dddot{i} \measuredangle \frac{1}{2} n$ dimensions et leurs marges," Publications de l'Institut de Statistique de l'Universiti $\ddot{z} \frac{1}{2}$ de Paris, 8, 229-231.

[42] Stokes, Donald E. 1963. "Spatial Models of Party Competition," American Political Science Review, 57, 368-377.

[43] Vicente, Pedro C. 2013. "Is Vote-buying Effective? Evidence from a Field Experiment in West Africa," Economic Journal, forthcoming.

[44] Vuong, Quang H. 1989. "Likelihood Ratio Tests for Model Selection and Non-Nested Hypotheses," Econometrica, 2, 307-333.

[45] Wantchekon, Leonard. 2003. "Clientelism and Voting Behavior: Evidence from a Field Experiment in Benin," World Politics, 55, 399-422.

[46] Wattenberg, Martin P. and Craig L. Brians. 1999. "Negative Campaign Advertising: Demobilizer or Mobilizer?" American Political Science Review, 93, 891-899.

[47] Zafar, Basit. 2009. "College Major Choice and the Gender Gap," Federal Reserve Bank of New York Staff Report No. 364. 


\section{Tables and Figures}

Table 1 - Election Results at a Glance

\begin{tabular}{lcccccc}
\hline \hline & Mean & Median & S.d. & Min & Max & Obs. \\
\hline Turnout & 0.708 & 0.714 & 0.050 & 0.389 & 0.788 & 95 \\
$\begin{array}{l}\text { Incumbent share } \\
\text { over valid votes }\end{array}$ & 0.513 & 0.508 & 0.061 & 0.354 & 0.667 & 95 \\
$\begin{array}{l}\text { Incumbent parties } \\
\text { over valid votes }\end{array}$ & 0.541 & 0.542 & 0.065 & 0.358 & 0.679 & 95 \\
& & & & & & \\
\hline $\begin{array}{l}\text { Notes. Descriptive statistics at the precinct level of the variables specified in the first column. "In- } \\
\text { cumbent parties" refer to the vote shares of the party lists supporting the incumbent. }\end{array}$
\end{tabular}

Table 2 - Vote Declarations at the Individual Level

\begin{tabular}{lcccccc}
\hline \hline & Mean & Median & S.d. & Min & Max & Obs. \\
\hline Declared turnout & 0.898 & 1.000 & 0.303 & 0.000 & 1.000 & 1,455
\end{tabular}

Declared vote

for the incumbent $\quad 0.571 \quad 1.000 \quad 0.495 \quad 0.000 \quad 1.000 \quad 1,306$

Declared vote

for incumbent parties $\quad 0.493 \quad 0.000 \quad 0.500 \quad 0.000 \quad 1.000 \quad 1,306$

Notes. Descriptive statistics at the individual level of the variables specified in the first column.

"Incumbent parties" refer to the (self-declared) vote in favor of the party lists supporting the incumbent. 
Table 3 - Reduced-Form Aggregate Estimates, All Groups

\begin{tabular}{|c|c|c|c|c|c|c|}
\hline & & & eference grc & no messa & & \\
\hline & $\begin{array}{c}\text { Valence } \\
\text { by phone }\end{array}$ & $\begin{array}{l}\text { Valence } \\
\text { by mail }\end{array}$ & $\begin{array}{l}\text { Ideology } \\
\text { by phone }\end{array}$ & $\begin{array}{l}\text { Ideology } \\
\text { by mail }\end{array}$ & $\begin{array}{c}\text { Double } \\
\text { by phone }\end{array}$ & $\begin{array}{l}\text { Double } \\
\text { by mail }\end{array}$ \\
\hline Turnout & $\begin{array}{l}-0.011 \\
{[0.031]}\end{array}$ & $\begin{array}{l}-0.000 \\
{[0.015]}\end{array}$ & $\begin{array}{c}0.013 \\
{[0.011]}\end{array}$ & $\begin{array}{c}0.010 \\
{[0.013]}\end{array}$ & $\begin{array}{l}-0.006 \\
{[0.009]}\end{array}$ & $\begin{array}{l}-0.006 \\
{[0.013]}\end{array}$ \\
\hline $\begin{array}{l}\text { Incumbent } \\
\text { share }\end{array}$ & $\begin{array}{c}0.041^{* *} \\
{[0.019]}\end{array}$ & $\begin{array}{c}0.004 \\
{[0.025]}\end{array}$ & $\begin{array}{c}0.013 \\
{[0.016]}\end{array}$ & $\begin{array}{c}0.021 \\
{[0.025]}\end{array}$ & $\begin{array}{l}0.027^{*} \\
{[0.015]}\end{array}$ & $\begin{array}{l}-0.023 \\
{[0.015]}\end{array}$ \\
\hline $\begin{array}{l}\text { Incumbent } \\
\text { parties }\end{array}$ & $\begin{array}{l}0.032^{*} \\
{[0.018]}\end{array}$ & $\begin{array}{c}0.018 \\
{[0.023]}\end{array}$ & $\begin{array}{c}0.015 \\
{[0.016]}\end{array}$ & $\begin{array}{c}0.029 \\
{[0.026]}\end{array}$ & $\begin{array}{c}0.021 \\
{[0.014]}\end{array}$ & $\begin{array}{l}-0.015 \\
{[0.015]}\end{array}$ \\
\hline
\end{tabular}

Table 4 - Reduced-Form Aggregate Estimates, Phone Calls

\begin{tabular}{|c|c|c|c|}
\hline & \multicolumn{3}{|c|}{ Reference group: mail or no message } \\
\hline & $\begin{array}{c}\text { Valence } \\
\text { by phone }\end{array}$ & $\begin{array}{l}\text { Ideology } \\
\text { by phone }\end{array}$ & $\begin{array}{c}\text { Double } \\
\text { by phone }\end{array}$ \\
\hline Turnout & $\begin{array}{l}-0.012 \\
{[0.030]}\end{array}$ & $\begin{array}{c}0.012 \\
{[0.011]}\end{array}$ & $\begin{array}{l}-0.006 \\
{[0.010]}\end{array}$ \\
\hline $\begin{array}{l}\text { Incumbent } \\
\text { share }\end{array}$ & $\begin{array}{c}0.040^{* *} \\
{[0.019]}\end{array}$ & $\begin{array}{c}0.012 \\
{[0.015]}\end{array}$ & $\begin{array}{l}0.026^{*} \\
{[0.013]}\end{array}$ \\
\hline $\begin{array}{l}\text { Incumbent } \\
\text { parties }\end{array}$ & $\begin{array}{c}0.026 \\
{[0.020]}\end{array}$ & $\begin{array}{c}0.008 \\
{[0.016]}\end{array}$ & $\begin{array}{c}0.014 \\
{[0.012]}\end{array}$ \\
\hline
\end{tabular}


Table 5 - Reduced-Form Individual Estimates, All Groups

\begin{tabular}{|c|c|c|c|c|c|c|}
\hline & & & eference gr & no messa & & \\
\hline & $\begin{array}{l}\text { Valence } \\
\text { by phone }\end{array}$ & $\begin{array}{l}\text { Valence } \\
\text { by mail }\end{array}$ & $\begin{array}{l}\text { Ideology } \\
\text { by phone }\end{array}$ & $\begin{array}{l}\text { Ideology } \\
\text { by mail }\end{array}$ & $\begin{array}{c}\text { Double } \\
\text { by phone }\end{array}$ & $\begin{array}{l}\text { Double } \\
\text { by mail }\end{array}$ \\
\hline Turnout & $\begin{array}{l}-0.024 \\
{[0.027]}\end{array}$ & $\begin{array}{l}-0.019 \\
{[0.034]}\end{array}$ & $\begin{array}{c}0.006 \\
{[0.026]}\end{array}$ & $\begin{array}{c}0.033 \\
{[0.022]}\end{array}$ & $\begin{array}{l}-0.019 \\
{[0.028]}\end{array}$ & $\begin{array}{l}-0.003 \\
{[0.029]}\end{array}$ \\
\hline $\begin{array}{l}\text { Incumbent } \\
\text { share }\end{array}$ & $\begin{array}{c}0.095 * * \\
{[0.039]}\end{array}$ & $\begin{array}{l}-0.061 \\
{[0.049]}\end{array}$ & $\begin{array}{c}0.018 \\
{[0.049]}\end{array}$ & $\begin{array}{l}-0.028 \\
{[0.043]}\end{array}$ & $\begin{array}{c}0.035 \\
{[0.050]}\end{array}$ & $\begin{array}{c}0.004 \\
{[0.050]}\end{array}$ \\
\hline $\begin{array}{l}\text { Incumbent } \\
\text { parties }\end{array}$ & $\begin{array}{c}0.109^{* * *} \\
{[0.040]}\end{array}$ & $\begin{array}{l}-0.007 \\
{[0.060]}\end{array}$ & $\begin{array}{l}-0.008 \\
{[0.061]}\end{array}$ & $\begin{array}{l}-0.044 \\
{[0.046]}\end{array}$ & $\begin{array}{c}0.009 \\
{[0.051]}\end{array}$ & $\begin{array}{l}-0.014 \\
{[0.049]}\end{array}$ \\
\hline
\end{tabular}

Table 6 - Reduced-Form Individual Estimates, Phone Calls

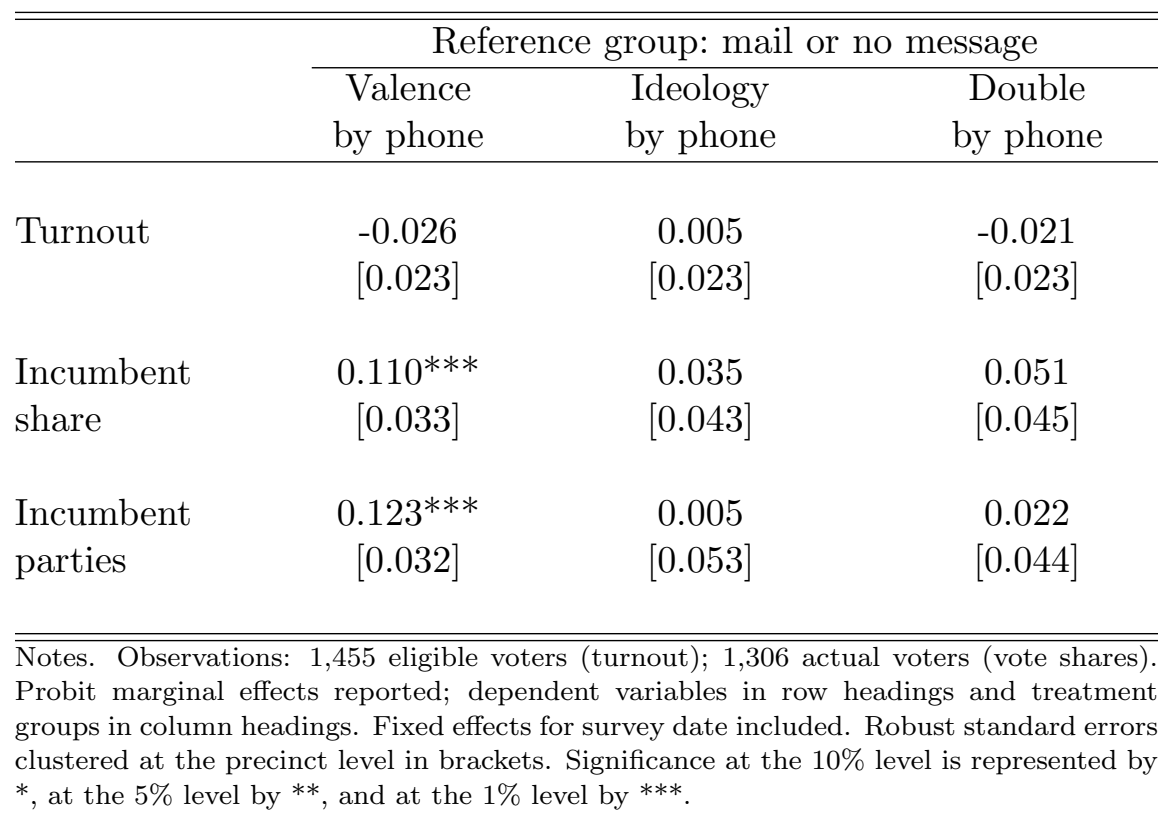


Table 7 - Model Estimates, Baseline Specification

\begin{tabular}{|c|c|}
\hline $\begin{array}{l}\text { Model's } \\
\text { parameters }\end{array}$ & $\begin{array}{c}\text { Estimate } \\
\text { [s.e.] }\end{array}$ \\
\hline$\beta_{A}=\operatorname{Pr}($ response $\mid \mathrm{A})$ & $\begin{array}{c}0.76 \\
{[0.01]}\end{array}$ \\
\hline$\beta_{B}=\operatorname{Pr}($ response $\mid \mathrm{B})$ & $\begin{array}{c}0.99 \\
{[0.01]}\end{array}$ \\
\hline$\gamma^{L}$ & $\begin{array}{c}1.08 \\
{[0.21]}\end{array}$ \\
\hline$\gamma^{C}$ & $\begin{array}{c}1.10 \\
{[0.14]}\end{array}$ \\
\hline$\gamma^{R}$ & $\begin{array}{c}0.37 \\
{[0.13]}\end{array}$ \\
\hline$\zeta^{L}$ & $\begin{array}{c}0.34 \\
{[0.21]}\end{array}$ \\
\hline$\zeta^{C}$ & $\begin{array}{c}0.00 \\
{[0.49]}\end{array}$ \\
\hline$\zeta^{R}$ & $\begin{array}{c}0.98 \\
{[0.32]}\end{array}$ \\
\hline$\chi^{L}$ & $\begin{array}{c}0.18 \\
{[0.14]}\end{array}$ \\
\hline$\chi^{C}$ & $\begin{array}{c}0.02 \\
{[0.09]}\end{array}$ \\
\hline$\chi^{R}$ & $\begin{array}{l}-0.03 \\
{[0.05]}\end{array}$ \\
\hline$\phi_{V, 3}$ & $\begin{array}{c}0.40 \\
{[0.15]}\end{array}$ \\
\hline$\phi_{V, 2}$ & $\begin{array}{c}0.40 \\
{[0.28]}\end{array}$ \\
\hline$\alpha_{V}$ & $\begin{array}{c}0.56 \\
{[0.05]}\end{array}$ \\
\hline$\phi_{P, 3}$ & $\begin{array}{c}0.58 \\
{[0.16]}\end{array}$ \\
\hline$\phi_{P, 2}$ & $\begin{array}{c}0.38 \\
{[0.19]}\end{array}$ \\
\hline$\alpha_{P}$ & $\begin{array}{c}0.71 \\
{[0.19]}\end{array}$ \\
\hline Loglikelihood & $-1,043.60$ \\
\hline Observations & 1,306 \\
\hline
\end{tabular}


Table 8 - Beliefs about Incumbent from Model Estimates

\begin{tabular}{|c|c|c|c|}
\hline & \multicolumn{3}{|c|}{ Reference group: mail or no message } \\
\hline & $\begin{array}{c}\text { Valence } \\
\text { by phone }\end{array}$ & $\begin{array}{l}\text { Ideology } \\
\text { by phone }\end{array}$ & $\begin{array}{c}\text { Double } \\
\text { by phone }\end{array}$ \\
\hline $\begin{array}{l}\text { Average } \\
\text { valence }\end{array}$ & $\begin{array}{c}0.310^{* *} \\
{[0.148]}\end{array}$ & $\begin{array}{l}-0.022 \\
{[0.142]}\end{array}$ & $\begin{array}{l}-0.100 \\
{[0.098]}\end{array}$ \\
\hline $\begin{array}{l}\text { Valence } \\
\text { std. dev. }\end{array}$ & $\begin{array}{c}0.005 \\
{[0.082]}\end{array}$ & $\begin{array}{c}0.063 \\
{[0.095]}\end{array}$ & $\begin{array}{c}0.025 \\
{[0.093]}\end{array}$ \\
\hline $\begin{array}{l}\text { Average } \\
\text { ideology }\end{array}$ & $\begin{array}{c}0.015 \\
{[0.063]}\end{array}$ & $\begin{array}{c}-0.121^{* *} \\
{[0.056]}\end{array}$ & $\begin{array}{c}-0.102^{*} \\
{[0.055]}\end{array}$ \\
\hline $\begin{array}{l}\text { Ideology } \\
\text { std. dev. }\end{array}$ & $\begin{array}{l}-0.036 \\
{[0.060]}\end{array}$ & $\begin{array}{c}-0.090^{* *} \\
{[0.039]}\end{array}$ & $\begin{array}{c}-0.127^{* * *} \\
{[0.044]}\end{array}$ \\
\hline
\end{tabular}

Table 9 - Beliefs about Incumbent from Survey Responses

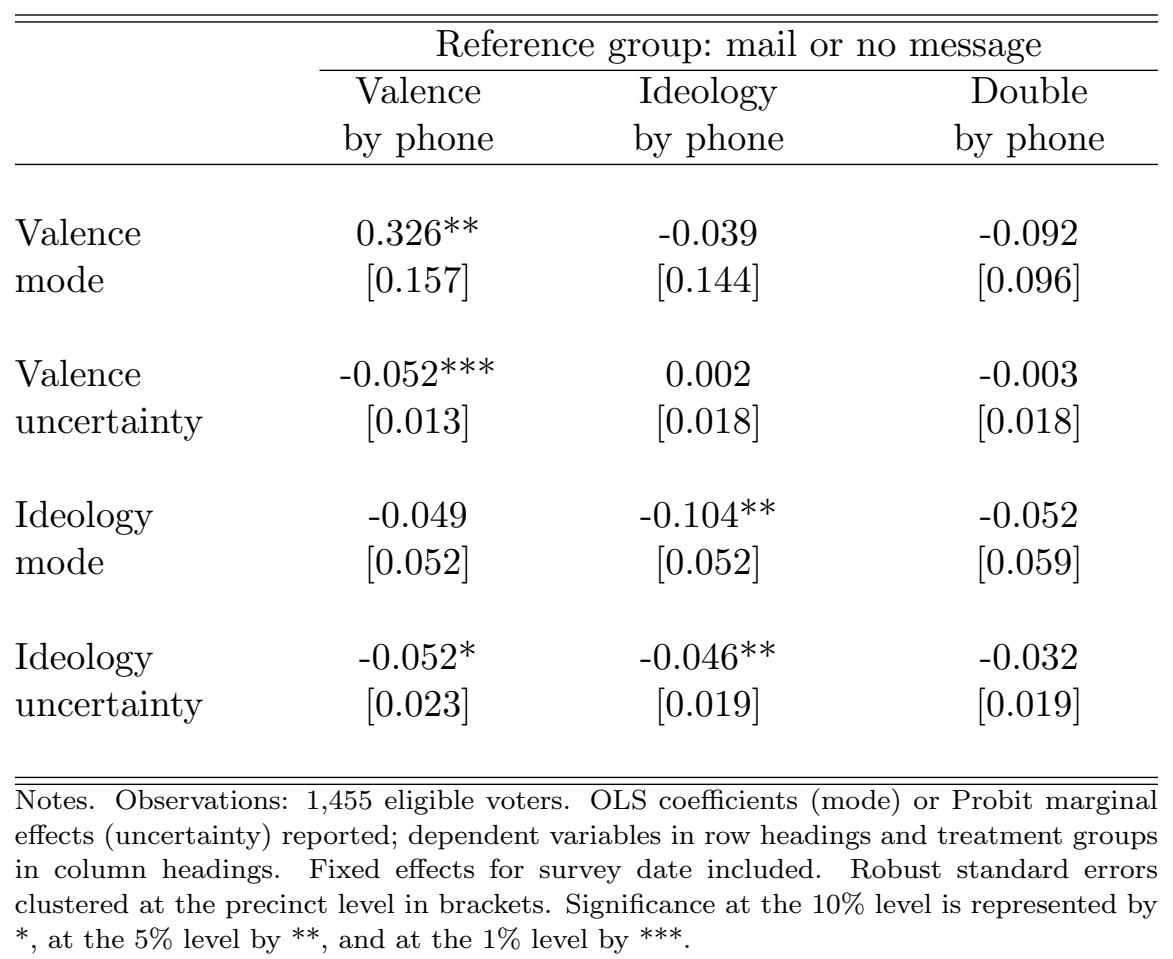


Table 10 - Beliefs about Opponent from Model Estimates

\begin{tabular}{|c|c|c|c|}
\hline & \multicolumn{3}{|c|}{ Reference group: mail or no message } \\
\hline & $\begin{array}{c}\text { Valence } \\
\text { by phone }\end{array}$ & $\begin{array}{l}\text { Ideology } \\
\text { by phone }\end{array}$ & $\begin{array}{c}\text { Double } \\
\text { by phone }\end{array}$ \\
\hline $\begin{array}{l}\text { Average } \\
\text { valence }\end{array}$ & $\begin{array}{l}-0.127 \\
{[0.081]}\end{array}$ & $\begin{array}{l}-0.045 \\
{[0.133]}\end{array}$ & $\begin{array}{l}-0.071 \\
{[0.094]}\end{array}$ \\
\hline $\begin{array}{l}\text { Valence } \\
\text { std. dev. }\end{array}$ & $\begin{array}{l}-0.077 \\
{[0.110]}\end{array}$ & $\begin{array}{l}-0.096 \\
{[0.107]}\end{array}$ & $\begin{array}{l}-0.048 \\
{[0.132]}\end{array}$ \\
\hline $\begin{array}{l}\text { Average } \\
\text { ideology }\end{array}$ & $\begin{array}{l}-0.075 \\
{[0.067]}\end{array}$ & $\begin{array}{c}0.189 * * \\
{[0.075]}\end{array}$ & $\begin{array}{l}-0.032 \\
{[0.070]}\end{array}$ \\
\hline $\begin{array}{l}\text { Ideology } \\
\text { std. dev. }\end{array}$ & $\begin{array}{c}0.041 \\
{[0.075]}\end{array}$ & $\begin{array}{c}-0.177^{* * *} \\
{[0.064]}\end{array}$ & $\begin{array}{l}-0.091 \\
{[0.057]}\end{array}$ \\
\hline
\end{tabular}

Table 11 - Beliefs about Opponent from Survey Responses

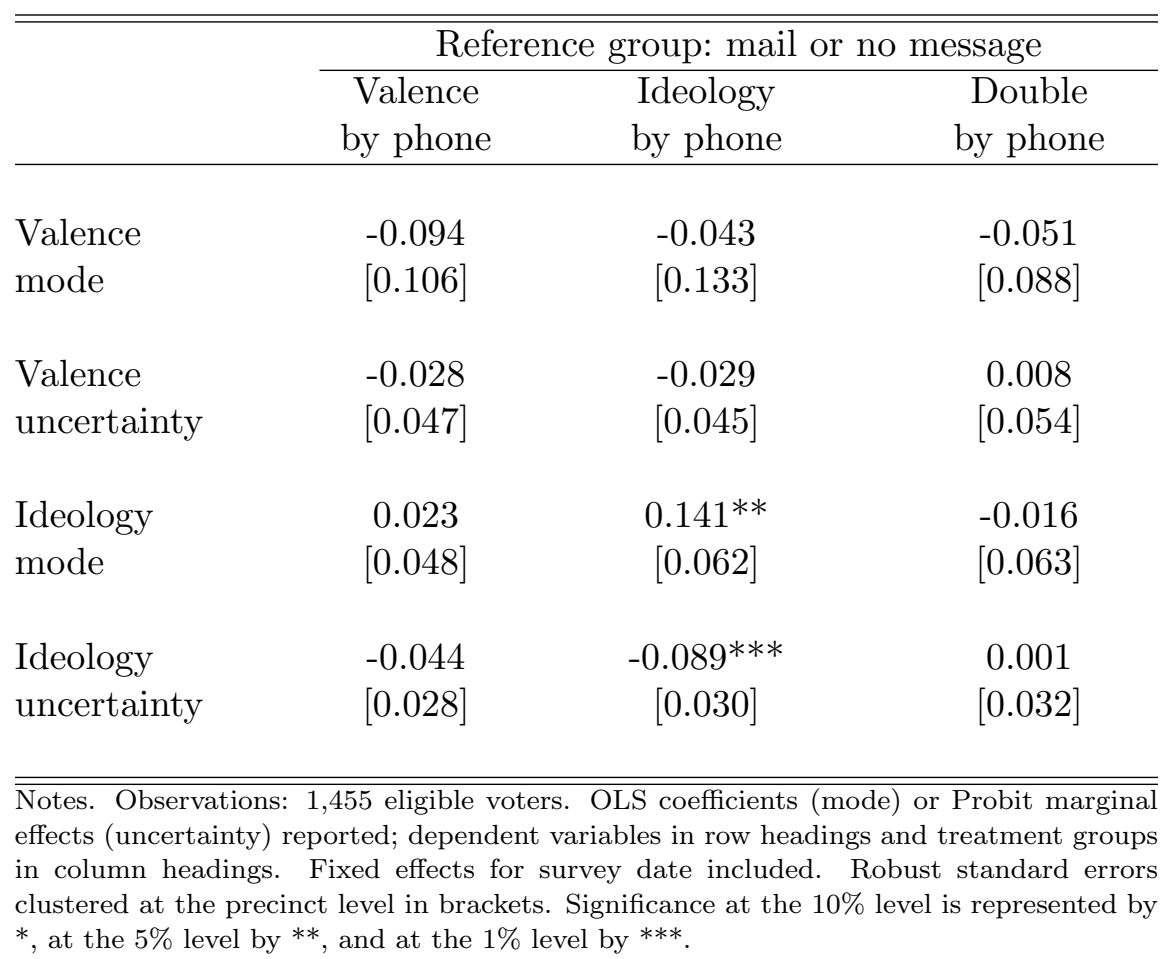


Table 12 - Predicted Vote Differences under Counterfactual Electoral Campaigns

\begin{tabular}{cc}
\hline \hline Counterfactual treatment & $\begin{array}{c}\text { Predicted vote difference } \\
\text { in percentage points }\end{array}$ \\
\hline
\end{tabular}

Blanket valence

2.2

treatment

$[0.77,3.33]$

Blanket ideology

$-2.2$

treatment

$[-3.37,-0.27]$

Blanket valence \& ideology

0.5

treatment

$[-0.73,1.84]$

Valence treatment to center \& right

1.3

valence \& ideology to left voters

$[-0.19,2.37]$

Ideology treatment to center \& right

$-2.4$

valence \& ideology to left voters

Actual electoral

1.8

campaign effect

$[1.23,3.14]$

$\overline{\text { Notes. Counterfactual additional votes (in percentage points) that candidate A would have obtained with }}$ the simulated campaigns described in the first column relative to no electoral treatment being administered. Bootstrapped 95 percent confidence intervals in brackets. Confidence intervals are based on 1,000 draws from the asymptotic distribution of the ML parameter vectors. 
Figure 1 - Prior Valence Marginal Distribution for Voter \#371

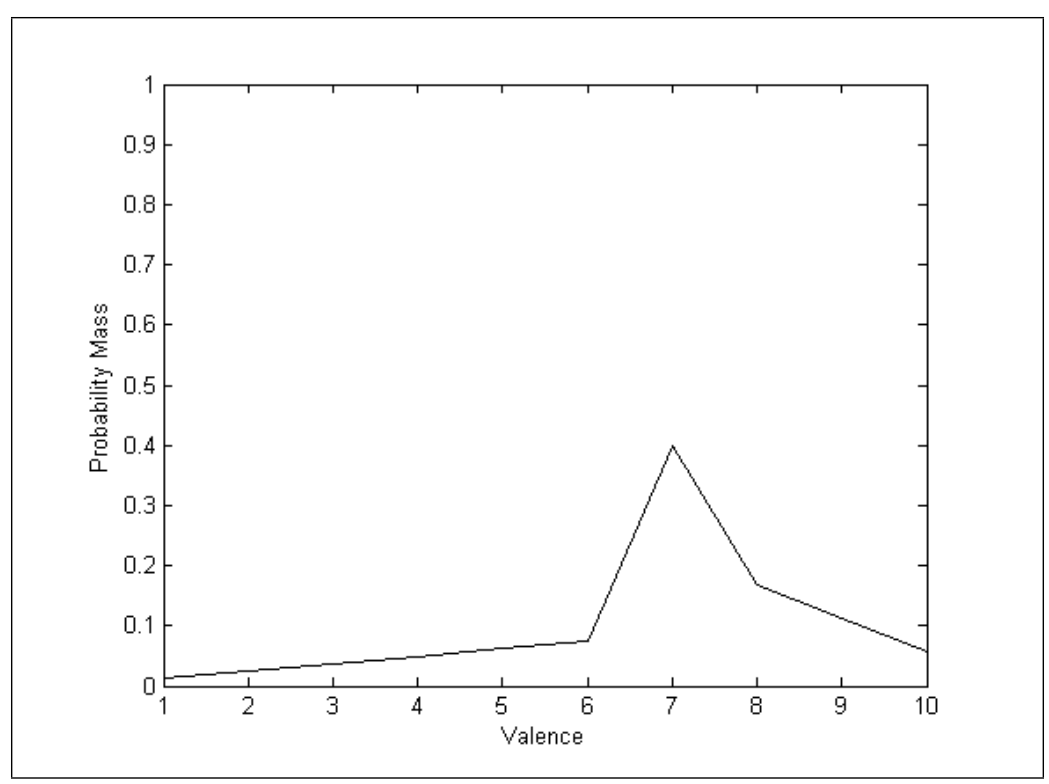

Figure 2 - Prior Joint Probability Distribution for Voter \#369

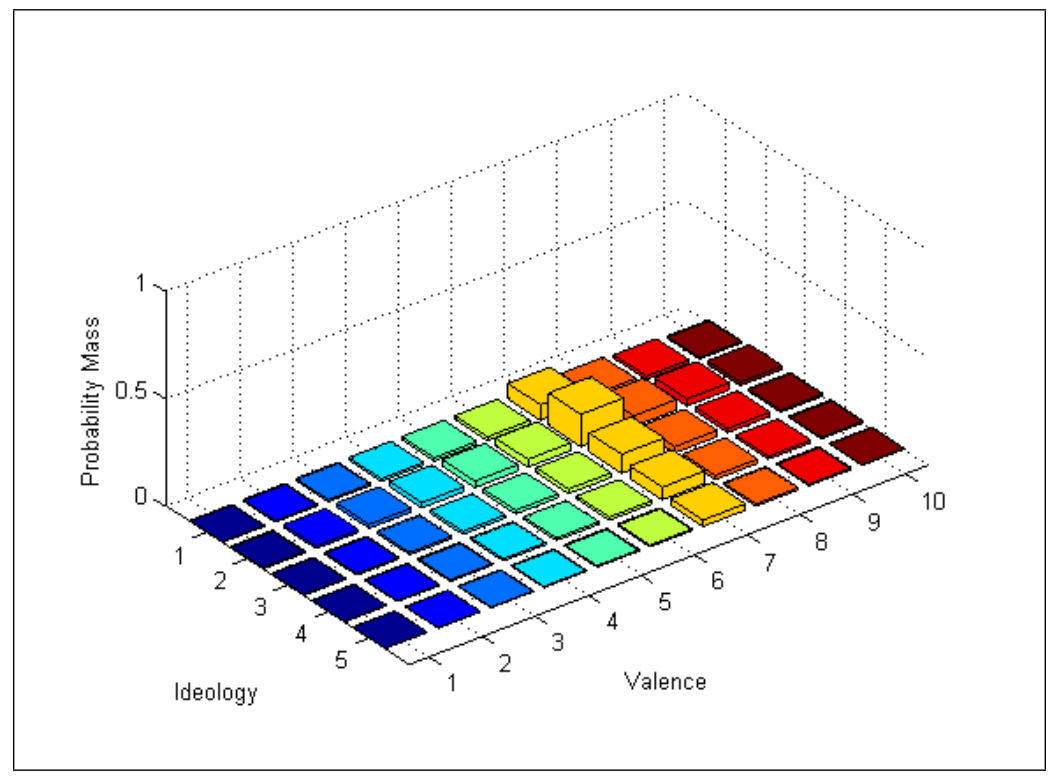


Figure 3 - Posterior Joint Probability Distribution for Voter \#369

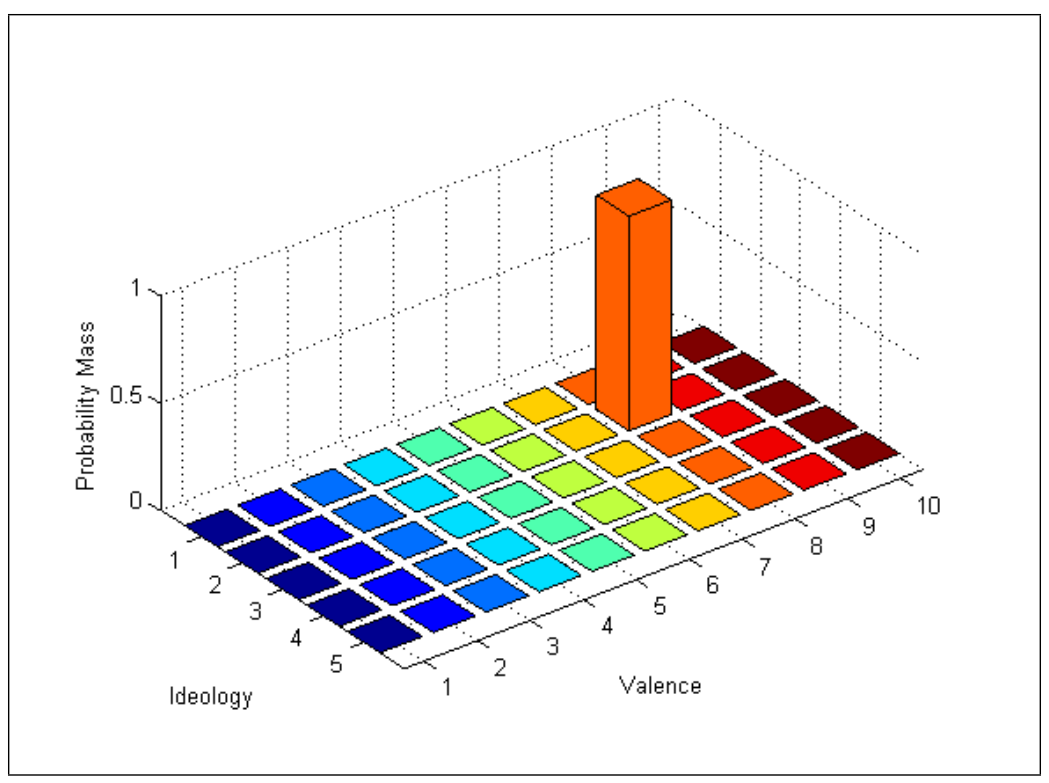




\section{Appendix}

For all materials related to the design of our randomized controlled trial (including survey questionnaires; colored treatment flyers; audio files of the treatment phone calls; and maps of the treatment groups) please refer to the website: www.igier.unibocconi.it/randomized-campaign.

In the next two subsections, we report the English translations of the text of the mail flyers (which are then showed in Figure A1 and Figure A2) and of the text of the candidate's recorded messages for the campaign phone calls.

In the subsection devoted to tables and figures, we report:

- balancing tests of precinct characteristics across treatment groups (Table A1);

- balancing tests of individual characteristics across treatment groups (Table A2);

- balancing tests of 2001 Census characteristics across treatment groups (Table A3);

- estimates of potential spillover effects (Table A4);

- complete summary of the structural model estimations (Tables A5 and A6);

- LR and Voung tests of model selection (Tables A7, A8, and A9);

- flyers for both the valence and ideology message (Figures A1 and A2).

\section{A1 Mail Flyers: English Translations}

Valence flyer. COMPETENCE AND EFFORT. 100 million worth of investments: Spent in part on the Fortress, squares, streets, and parking lots. PIUSS, the integrated plan for the development of the city: The city of Arezzo was ranked first in Tuscany; this is an important accomplishment. Innovation: The digital center, the hydrogen pipeline, and the energy house. FANFANI FOR MAYOR.

Ideology flyer. AWARENESS AND SOLIDARITY. Children: Created an integrated system to cater the needs of all, opened 3 new public nursery schools. Elderly: In-home assistance, new public services to help families. A network of solidarity for the neediest: Housing, meal centers, work integration services. FANFANI FOR MAYOR.

\section{A2 Phone Call Recorded Messages: English Translations}

Valence message. Dear Voter, the 15th and 16th of May, the citizens of Arezzo will vote to elect the mayor and city councilmen. We all therefore have the opportunity to make an informed choice for the future of Arezzo. Over the last years, my administration invested 100 million Euros to develop and improve our city. Results are under the eyes of everyone and can be observed by simply looking at the Fortress, the squares, the streets, and the parking lots. Thanks to the quality of our 
work, the PIUSS - the plan for the development of the city of Arezzo-was ranked first among those in Tuscany. This was an important accomplishment that also enabled us to gain access to important financial resources to improve the prominence of our city. However, we did much more than this, we strived to boost innovation with the digital center, the hydrogen pipeline, and the energy house. Given also all these reasons, I take the liberty to ask for your vote in the election of the 15th and 16th of May. Reward our COMPETENCE and our EFFORT. Best regards from Giuseppe Fanfani.

Ideology message. Dear Voter, the 15th and 16th of May, the citizens of Arezzo will vote to elect the mayor and city councilmen. We all will have the opportunity to make an informed choice for the future of Arezzo. For us, future stands for SOLIDARITY. In these five years of city government, we dealt with issues regarding childhood creating an integrated system of services able to provide answers to all families and opening three new public nursery schools. We also took care of our elderly people, providing new services to help families assist them and increasing in-home assistance. At the same time, we definitely did not forget about those that found themselves living in difficult circumstances also because they were affected by the international crisis that severely struck our region. In fact, we increased housing, meal centers, and professional integration services for all those in need. Given also all these reasons, I take the liberty to ask for your vote in the election of the 15th and 16th of May. Make SOLIDARITY win! For an "Arezzo" careful and open to the hardships of those in need. Best regards from Giuseppe Fanfani.

Valence plus ideology message. Dear Voter, the 15th and 16th of May, the citizens of Arezzo will vote to elect the mayor and city councilmen. We all therefore have the opportunity to make an informed choice for the future of Arezzo. Over the last years, my administration invested 100 million Euros to develop and improve our city. Results are under the eyes of everyone and can observed by simply looking at the Fortress, the squares, the streets, and the parking lots. Thanks to the quality of our work, the PIUSS - the plan for the development of the city of Arezzo-was ranked first among those in Tuscany. At the same time, we definitely did not forget about those that found themselves living in difficult circumstances also because they were affected by the international crisis that severely struck our region. In fact, we increased housing, meal centers, and professional integration services for all those in need. Given also all these reasons, I take the liberty to ask for your vote in the election of the 15th and 16th of May. Reward our COMPETENCE and our EFFORT. Make SOLIDARITY win! For an Arezzo careful and open to the hardships of those in need. Best regards from Giuseppe Fanfani. 


\section{Appendix Tables and Figures}

Table A1 - Ex-Ante Balancing Tests at the Precinct Level

\begin{tabular}{|c|c|c|c|c|c|c|}
\hline & & & eference gr & no messag & & \\
\hline & $\begin{array}{c}\text { Valence } \\
\text { by phone }\end{array}$ & $\begin{array}{l}\text { Valence } \\
\text { by mail }\end{array}$ & $\begin{array}{l}\text { Ideology } \\
\text { by phone }\end{array}$ & $\begin{array}{r}\text { Ideology } \\
\text { by mail }\end{array}$ & $\begin{array}{c}\text { Double } \\
\text { by phone }\end{array}$ & $\begin{array}{l}\text { Double } \\
\text { by mail }\end{array}$ \\
\hline Eligible voters & $\begin{array}{l}-66.083 \\
{[96.591]}\end{array}$ & $\begin{array}{r}-101.583 \\
{[70.235]}\end{array}$ & $\begin{array}{c}19.250 \\
{[57.771]}\end{array}$ & $\begin{array}{c}-63.667^{*} \\
{[36.922]}\end{array}$ & $\begin{array}{l}-65.500 \\
{[66.886]}\end{array}$ & $\begin{array}{c}-6.083 \\
{[56.033]}\end{array}$ \\
\hline First neighborhood & $\begin{array}{c}0.036 \\
{[0.136]}\end{array}$ & $\begin{array}{c}0.036 \\
{[0.112]}\end{array}$ & $\begin{array}{c}0.203 \\
{[0.178]}\end{array}$ & $\begin{array}{l}-0.047 \\
{[0.112]}\end{array}$ & $\begin{array}{c}0.203 \\
{[0.123]}\end{array}$ & $\begin{array}{l}-0.047 \\
{[0.109]}\end{array}$ \\
\hline Second neighborhood & $\begin{array}{c}0.116 \\
{[0.188]}\end{array}$ & $\begin{array}{l}-0.051 \\
{[0.140]}\end{array}$ & $\begin{array}{l}-0.051 \\
{[0.151]}\end{array}$ & $\begin{array}{l}-0.051 \\
{[0.154]}\end{array}$ & $\begin{array}{l}-0.051 \\
{[0.086]}\end{array}$ & $\begin{array}{c}0.033 \\
{[0.128]}\end{array}$ \\
\hline Third neighborhood & $\begin{array}{l}-0.014 \\
{[0.190]}\end{array}$ & $\begin{array}{c}0.236 \\
{[0.172]}\end{array}$ & $\begin{array}{l}-0.098 \\
{[0.134]}\end{array}$ & $\begin{array}{c}0.152 \\
{[0.199]}\end{array}$ & $\begin{array}{l}-0.014 \\
{[0.169]}\end{array}$ & $\begin{array}{l}-0.098 \\
{[0.134]}\end{array}$ \\
\hline Fourth neighborhood & $\begin{array}{l}-0.138 \\
{[0.149]}\end{array}$ & $\begin{array}{l}-0.221 \\
{[0.141]}\end{array}$ & $\begin{array}{l}-0.054 \\
{[0.146]}\end{array}$ & $\begin{array}{l}-0.054 \\
{[0.164]}\end{array}$ & $\begin{array}{l}-0.138 \\
{[0.139]}\end{array}$ & $\begin{array}{c}0.112 \\
{[0.129]}\end{array}$ \\
\hline Regional '10 turnout & $\begin{array}{l}-0.005 \\
{[0.025]}\end{array}$ & $\begin{array}{l}-0.003 \\
{[0.016]}\end{array}$ & $\begin{array}{c}0.016 \\
{[0.010]}\end{array}$ & $\begin{array}{c}0.012 \\
{[0.010]}\end{array}$ & $\begin{array}{c}0.000 \\
{[0.010]}\end{array}$ & $\begin{array}{l}-0.002 \\
{[0.014]}\end{array}$ \\
\hline Regional '10 left & $\begin{array}{c}0.011 \\
{[0.015]}\end{array}$ & $\begin{array}{c}0.013 \\
{[0.019]}\end{array}$ & $\begin{array}{c}0.013 \\
{[0.013]}\end{array}$ & $\begin{array}{c}0.012 \\
{[0.017]}\end{array}$ & $\begin{array}{c}0.004 \\
{[0.013]}\end{array}$ & $\begin{array}{l}-0.021 \\
{[0.013]}\end{array}$ \\
\hline Regional '10 right & $\begin{array}{l}-0.015 \\
{[0.015]}\end{array}$ & $\begin{array}{l}-0.017 \\
{[0.014]}\end{array}$ & $\begin{array}{c}0.011 \\
{[0.012]}\end{array}$ & $\begin{array}{c}0.007 \\
{[0.018]}\end{array}$ & $\begin{array}{l}-0.006 \\
{[0.011]}\end{array}$ & $\begin{array}{c}0.019 \\
{[0.018]}\end{array}$ \\
\hline European '09 turnout & $\begin{array}{l}-0.004 \\
{[0.026]}\end{array}$ & $\begin{array}{c}0.008 \\
{[0.012]}\end{array}$ & $\begin{array}{c}0.019 \\
{[0.012]}\end{array}$ & $\begin{array}{c}0.013 \\
{[0.013]}\end{array}$ & $\begin{array}{c}0.002 \\
{[0.011]}\end{array}$ & $\begin{array}{c}0.007 \\
{[0.012]}\end{array}$ \\
\hline European '09 left & $\begin{array}{l}-0.012 \\
{[0.030]}\end{array}$ & $\begin{array}{c}0.015 \\
{[0.026]}\end{array}$ & $\begin{array}{l}-0.016 \\
{[0.016]}\end{array}$ & $\begin{array}{l}-0.014 \\
{[0.025]}\end{array}$ & $\begin{array}{c}0.018 \\
{[0.019]}\end{array}$ & $\begin{array}{l}-0.028 \\
{[0.021]}\end{array}$ \\
\hline European '09 right & $\begin{array}{c}0.009 \\
{[0.022]}\end{array}$ & $\begin{array}{l}-0.015 \\
{[0.021]}\end{array}$ & $\begin{array}{c}0.018 \\
{[0.015]}\end{array}$ & $\begin{array}{c}0.009 \\
{[0.024]}\end{array}$ & $\begin{array}{l}-0.014 \\
{[0.020]}\end{array}$ & $\begin{array}{c}0.026 \\
{[0.020]}\end{array}$ \\
\hline National '08 turnout & $\begin{array}{l}-0.014 \\
{[0.025]}\end{array}$ & $\begin{array}{c}0.012 \\
{[0.008]}\end{array}$ & $\begin{array}{c}0.002 \\
{[0.006]}\end{array}$ & $\begin{array}{c}0.002 \\
{[0.007]}\end{array}$ & $\begin{array}{c}0.005 \\
{[0.007]}\end{array}$ & $\begin{array}{c}0.000 \\
{[0.009]}\end{array}$ \\
\hline National '08 left & $\begin{array}{c}0.016 \\
{[0.019]}\end{array}$ & $\begin{array}{c}0.026 \\
{[0.019]}\end{array}$ & $\begin{array}{l}-0.015 \\
{[0.019]}\end{array}$ & $\begin{array}{l}-0.004 \\
{[0.028]}\end{array}$ & $\begin{array}{c}0.020 \\
{[0.020]}\end{array}$ & $\begin{array}{l}-0.019 \\
{[0.017]}\end{array}$ \\
\hline National '08 right & $\begin{array}{l}-0.018 \\
{[0.020]}\end{array}$ & $\begin{array}{l}-0.023 \\
{[0.017]}\end{array}$ & $\begin{array}{c}0.013 \\
{[0.017]}\end{array}$ & $\begin{array}{c}0.004 \\
{[0.028]}\end{array}$ & $\begin{array}{l}-0.024 \\
{[0.021]}\end{array}$ & $\begin{array}{c}0.023 \\
{[0.018]}\end{array}$ \\
\hline City '06 turnout & $\begin{array}{l}-0.002 \\
{[0.020]}\end{array}$ & $\begin{array}{c}0.008 \\
{[0.011]}\end{array}$ & $\begin{array}{c}0.012 \\
{[0.009]}\end{array}$ & $\begin{array}{c}0.009 \\
{[0.013]}\end{array}$ & $\begin{array}{c}0.011 \\
{[0.011]}\end{array}$ & $\begin{array}{l}-0.006 \\
{[0.013]}\end{array}$ \\
\hline City '06 left & $\begin{array}{c}0.016 \\
{[0.029]}\end{array}$ & $\begin{array}{c}0.035 \\
{[0.024]}\end{array}$ & $\begin{array}{l}-0.029 \\
{[0.023]}\end{array}$ & $\begin{array}{l}-0.017 \\
{[0.034]}\end{array}$ & $\begin{array}{c}0.009 \\
{[0.021]}\end{array}$ & $\begin{array}{l}-0.029 \\
{[0.022]}\end{array}$ \\
\hline City '06 right & $\begin{array}{l}-0.014 \\
{[0.029]}\end{array}$ & $\begin{array}{l}-0.037 \\
{[0.024]}\end{array}$ & $\begin{array}{c}0.028 \\
{[0.022]}\end{array}$ & $\begin{array}{c}0.014 \\
{[0.033]}\end{array}$ & $\begin{array}{l}-0.008 \\
{[0.021]}\end{array}$ & $\begin{array}{c}0.022 \\
{[0.024]}\end{array}$ \\
\hline
\end{tabular}

Notes. Observations: 95 precincts, 86 (European), 84 (National), 83 (City). OLS coefficients reported; dependent variables in row headings and treatment groups in column headings. Eligible voters is the number of eligible voters in the precinct (average 820.168). The neighborhood dummies capture the city-wide neighborhood the precinct belongs to. The other variables are the electoral outcomes in past elections and are expressed as vote shares. Robust standard errors clustered at the polling place level in brackets. Significance at the $10 \%$ level is represented by ${ }^{*}$, at the $5 \%$ level by ${ }^{* *}$, and at the $1 \%$ level by ${ }^{* * *}$. 
Table A2 - Ex-Post Balancing Tests at the Individual Level

\begin{tabular}{|c|c|c|c|c|c|c|}
\hline & \multicolumn{6}{|c|}{ Reference group: no message } \\
\hline & $\begin{array}{c}\text { Valence } \\
\text { by phone }\end{array}$ & $\begin{array}{l}\text { Valence } \\
\text { by mail }\end{array}$ & $\begin{array}{l}\text { Ideology } \\
\text { by phone }\end{array}$ & $\begin{array}{l}\text { Ideology } \\
\text { by mail }\end{array}$ & $\begin{array}{c}\text { Double } \\
\text { by phone }\end{array}$ & $\begin{array}{l}\text { Double } \\
\text { by mail }\end{array}$ \\
\hline Male & $\begin{array}{c}0.008 \\
{[0.039]}\end{array}$ & $\begin{array}{c}0.014 \\
{[0.050]}\end{array}$ & $\begin{array}{c}0.034 \\
{[0.038]}\end{array}$ & $\begin{array}{c}0.004 \\
{[0.038]}\end{array}$ & $\begin{array}{c}0.006 \\
{[0.047]}\end{array}$ & $\begin{array}{c}0.042 \\
{[0.039]}\end{array}$ \\
\hline Over 65 & $\begin{array}{l}-0.035 \\
{[0.053]}\end{array}$ & $\begin{array}{c}0.004 \\
{[0.048]}\end{array}$ & $\begin{array}{l}-0.012 \\
{[0.048]}\end{array}$ & $\begin{array}{c}0.086 \\
{[0.053]}\end{array}$ & $\begin{array}{l}-0.046 \\
{[0.042]}\end{array}$ & $\begin{array}{c}0.056 \\
{[0.048]}\end{array}$ \\
\hline $\begin{array}{l}\text { College } \\
\text { graduate }\end{array}$ & $\begin{array}{l}-0.004 \\
{[0.035]}\end{array}$ & $\begin{array}{l}-0.027 \\
{[0.041]}\end{array}$ & $\begin{array}{c}0.010 \\
{[0.041]}\end{array}$ & $\begin{array}{c}0.008 \\
{[0.047]}\end{array}$ & $\begin{array}{c}0.035 \\
{[0.045]}\end{array}$ & $\begin{array}{l}-0.016 \\
{[0.040]}\end{array}$ \\
\hline $\begin{array}{l}\text { Out of } \\
\text { labor force }\end{array}$ & $\begin{array}{l}-0.019 \\
{[0.052]}\end{array}$ & $\begin{array}{c}0.010 \\
{[0.054]}\end{array}$ & $\begin{array}{l}-0.037 \\
{[0.058]}\end{array}$ & $\begin{array}{c}0.048 \\
{[0.059]}\end{array}$ & $\begin{array}{l}-0.041 \\
{[0.050]}\end{array}$ & $\begin{array}{c}0.050 \\
{[0.053]}\end{array}$ \\
\hline $\begin{array}{l}\text { White } \\
\text { collar }\end{array}$ & $\begin{array}{c}0.029 \\
{[0.045]}\end{array}$ & $\begin{array}{l}-0.005 \\
{[0.043]}\end{array}$ & $\begin{array}{c}0.032 \\
{[0.038]}\end{array}$ & $\begin{array}{l}-0.013 \\
{[0.041]}\end{array}$ & $\begin{array}{c}0.008 \\
{[0.039]}\end{array}$ & $\begin{array}{l}-0.013 \\
{[0.038]}\end{array}$ \\
\hline $\begin{array}{l}\text { Other } \\
\text { occupation }\end{array}$ & $\begin{array}{l}-0.010 \\
{[0.049]}\end{array}$ & $\begin{array}{l}-0.005 \\
{[0.041]}\end{array}$ & $\begin{array}{c}0.006 \\
{[0.040]}\end{array}$ & $\begin{array}{l}-0.035 \\
{[0.039]}\end{array}$ & $\begin{array}{c}0.033 \\
{[0.042]}\end{array}$ & $\begin{array}{l}-0.037 \\
{[0.051]}\end{array}$ \\
\hline Center-left & $\begin{array}{c}0.045 \\
{[0.044]}\end{array}$ & $\begin{array}{c}0.058 \\
{[0.055]}\end{array}$ & $\begin{array}{l}-0.009 \\
{[0.048]}\end{array}$ & $\begin{array}{l}-0.033 \\
{[0.040]}\end{array}$ & $\begin{array}{l}-0.059 \\
{[0.042]}\end{array}$ & $\begin{array}{c}0.014 \\
{[0.059]}\end{array}$ \\
\hline Home owner & $\begin{array}{l}-0.017 \\
{[0.040]}\end{array}$ & $\begin{array}{l}-0.007 \\
{[0.030]}\end{array}$ & $\begin{array}{l}-0.045 \\
{[0.039]}\end{array}$ & $\begin{array}{c}0.027 \\
{[0.036]}\end{array}$ & $\begin{array}{c}0.007 \\
{[0.033]}\end{array}$ & $\begin{array}{l}-0.037 \\
{[0.028]}\end{array}$ \\
\hline $\begin{array}{l}\text { Read } \\
\text { the press }\end{array}$ & $\begin{array}{c}0.037 \\
{[0.036]}\end{array}$ & $\begin{array}{l}-0.007 \\
{[0.038]}\end{array}$ & $\begin{array}{c}0.025 \\
{[0.042]}\end{array}$ & $\begin{array}{l}-0.024 \\
{[0.052]}\end{array}$ & $\begin{array}{c}0.032 \\
{[0.049]}\end{array}$ & $\begin{array}{c}0.048 \\
{[0.047]}\end{array}$ \\
\hline Watch TV & $\begin{array}{c}0.034 \\
{[0.042]}\end{array}$ & $\begin{array}{l}-0.016 \\
{[0.055]}\end{array}$ & $\begin{array}{c}0.038 \\
{[0.039]}\end{array}$ & $\begin{array}{c}0.068 \\
{[0.046]}\end{array}$ & $\begin{array}{l}-0.033 \\
{[0.042]}\end{array}$ & $\begin{array}{c}0.055 \\
{[0.038]}\end{array}$ \\
\hline
\end{tabular}

Notes. Observations: 1,455 eligible voters. OLS coefficients reported; dependent variables in row headings and treatment groups in column headings. All variables are dummies. Read the press and Watch TV capture whether the voter declares to do this "very often" or "often." Fixed effects for survey date included. Robust standard errors clustered at the precinct level in brackets. Significance at the $10 \%$ level is represented by $*$, at the $5 \%$ level by $* *$, and at the $1 \%$ level by ***. 
Table A3 - Ex-Post Balancing Tests of 2001 Census Characteristics

\begin{tabular}{|c|c|c|c|c|c|c|}
\hline & & & Reference $\mathrm{g}$ & no messag & & \\
\hline & $\begin{array}{l}\text { Valence } \\
\text { by phone }\end{array}$ & $\begin{array}{l}\text { Valence } \\
\text { by mail }\end{array}$ & $\begin{array}{l}\text { Ideology } \\
\text { by phone }\end{array}$ & $\begin{array}{l}\text { Ideology } \\
\text { by mail }\end{array}$ & $\begin{array}{c}\text { Double } \\
\text { by phone }\end{array}$ & $\begin{array}{l}\text { Double } \\
\text { by mail }\end{array}$ \\
\hline Males & $\begin{array}{l}-5.112 \\
{[7.450]}\end{array}$ & $\begin{array}{l}-1.318 \\
{[6.922]}\end{array}$ & $\begin{array}{l}-8.103 \\
{[6.353]}\end{array}$ & $\begin{array}{l}-1.957 \\
{[7.245]}\end{array}$ & $\begin{array}{l}-2.587 \\
{[5.220]}\end{array}$ & $\begin{array}{c}1.187 \\
{[8.773]}\end{array}$ \\
\hline Married people & $\begin{array}{l}-5.780 \\
{[8.041]}\end{array}$ & $\begin{array}{l}-1.608 \\
{[7.496]}\end{array}$ & $\begin{array}{l}-8.986 \\
{[6.905]}\end{array}$ & $\begin{array}{l}-2.040 \\
{[7.955]}\end{array}$ & $\begin{array}{l}-2.863 \\
{[5.697]}\end{array}$ & $\begin{array}{c}1.256 \\
{[9.541]}\end{array}$ \\
\hline College graduates & $\begin{array}{l}-0.507 \\
{[0.661]}\end{array}$ & $\begin{array}{c}0.093 \\
{[0.568]}\end{array}$ & $\begin{array}{l}-0.712 \\
{[0.492]}\end{array}$ & $\begin{array}{c}0.473 \\
{[0.725]}\end{array}$ & $\begin{array}{l}-0.177 \\
{[0.499]}\end{array}$ & $\begin{array}{c}0.748 \\
{[1.058]}\end{array}$ \\
\hline Foreigners & $\begin{array}{l}-0.400 \\
{[0.339]}\end{array}$ & $\begin{array}{l}-0.178 \\
{[0.339]}\end{array}$ & $\begin{array}{l}-0.311 \\
{[0.330]}\end{array}$ & $\begin{array}{l}-0.255 \\
{[0.339]}\end{array}$ & $\begin{array}{l}-0.395 \\
{[0.310]}\end{array}$ & $\begin{array}{l}-0.129 \\
{[0.395]}\end{array}$ \\
\hline Employment rate & $\begin{array}{c}0.002 \\
{[0.006]}\end{array}$ & $\begin{array}{l}-0.003 \\
{[0.006]}\end{array}$ & $\begin{array}{l}-0.000 \\
{[0.005]}\end{array}$ & $\begin{array}{l}-0.002 \\
{[0.004]}\end{array}$ & $\begin{array}{c}0.005 \\
{[0.005]}\end{array}$ & $\begin{array}{l}-0.001 \\
{[0.004]}\end{array}$ \\
\hline Unemployment rate & $\begin{array}{l}-0.001 \\
{[0.005]}\end{array}$ & $\begin{array}{c}0.004 \\
{[0.004]}\end{array}$ & $\begin{array}{c}0.001 \\
{[0.004]}\end{array}$ & $\begin{array}{c}0.000 \\
{[0.004]}\end{array}$ & $\begin{array}{l}-0.001 \\
{[0.005]}\end{array}$ & $\begin{array}{c}0.003 \\
{[0.004]}\end{array}$ \\
\hline Home ownership & $\begin{array}{c}0.011 \\
{[0.025]}\end{array}$ & $\begin{array}{l}-0.028 \\
{[0.038]}\end{array}$ & $\begin{array}{l}-0.012 \\
{[0.030]}\end{array}$ & $\begin{array}{l}-0.023 \\
{[0.025]}\end{array}$ & $\begin{array}{l}-0.012 \\
{[0.027]}\end{array}$ & $\begin{array}{l}-0.003 \\
{[0.025]}\end{array}$ \\
\hline
\end{tabular}

Notes. Observations: 95 precincts. OLS coefficients reported; dependent variables in row headings and treatment groups in column headings. All variables are imputed at the precinct level from information on the 2001 Census cells. Males, Married people, College graduates, and Foreigners capture the average number of individuals with that attribute at the precinct level. Employment rate, Unemployment rate, and Home ownership are expressed as shares. In particular, home ownership is the share of houses occupied by the owner. Robust standard errors clustered at the polling place level in brackets. Significance at the $10 \%$ level is represented by $*$, at the $5 \%$ level by $* *$, and at the $1 \%$ level by $* * *$. 
Table A4 - Evaluating Potential Spillovers, All Groups

\begin{tabular}{|c|c|c|c|c|c|c|}
\hline & \multicolumn{6}{|c|}{ Reference group: no message } \\
\hline & $\begin{array}{c}\text { Valence } \\
\text { by phone } \\
\text { spillovers }\end{array}$ & $\begin{array}{c}\text { Valence } \\
\text { by mail } \\
\text { spillovers }\end{array}$ & $\begin{array}{l}\text { Ideology } \\
\text { by phone } \\
\text { spillovers }\end{array}$ & $\begin{array}{c}\text { Ideology } \\
\text { by mail } \\
\text { spillovers }\end{array}$ & $\begin{array}{c}\text { Double } \\
\text { by phone } \\
\text { spillovers }\end{array}$ & $\begin{array}{c}\text { Double } \\
\text { by mail } \\
\text { spillovers }\end{array}$ \\
\hline Turnout & $\begin{array}{c}0.032 \\
{[0.048]}\end{array}$ & $\begin{array}{l}-0.034 \\
{[0.055]}\end{array}$ & $\begin{array}{c}0.010 \\
{[0.044]}\end{array}$ & $\begin{array}{c}0.047 \\
{[0.060]}\end{array}$ & $\begin{array}{c}0.003 \\
{[0.042]}\end{array}$ & $\begin{array}{c}0.028 \\
{[0.054]}\end{array}$ \\
\hline $\begin{array}{l}\text { Incumbent } \\
\text { share }\end{array}$ & $\begin{array}{c}0.099 \\
{[0.077]}\end{array}$ & $\begin{array}{l}-0.113 \\
{[0.082]}\end{array}$ & $\begin{array}{c}0.064 \\
{[0.080]}\end{array}$ & $\begin{array}{l}-0.020 \\
{[0.100]}\end{array}$ & $\begin{array}{c}0.124 \\
{[0.076]}\end{array}$ & $\begin{array}{c}0.005 \\
{[0.099]}\end{array}$ \\
\hline $\begin{array}{l}\text { Incumbent } \\
\text { parties }\end{array}$ & $\begin{array}{c}0.081 \\
{[0.079]}\end{array}$ & $\begin{array}{l}-0.147 \\
{[0.098]}\end{array}$ & $\begin{array}{l}-0.035 \\
{[0.096]}\end{array}$ & $\begin{array}{l}-0.118 \\
{[0.104]}\end{array}$ & $\begin{array}{c}0.038 \\
{[0.089]}\end{array}$ & $\begin{array}{c}0.006 \\
{[0.115]}\end{array}$ \\
\hline
\end{tabular}

Notes. Observations: 1,455 eligible voters (turnout); 1,306 actual voters (vote shares). OLS coefficients reported; dependent variables in row headings and treatment groups in column headings. Each spillovers variable captures the share of observations who received the corresponding treatment in the same polling place of every observation. Average values are: 0.135 (valence by phone); 0.099 (valence by mail); 0.151 (ideology by phone); 0.106 (ideology by mail); 0.135 (double by phone); 0.113 (double by mail). Fixed effects for survey date included. Robust standard errors clustered at the precinct level in brackets. Significance at the $10 \%$ level is represented by ${ }^{*}$, at the $5 \%$ level by $* *$, and at the $1 \%$ level by ***. 
Table A5 - Model Estimates with Heterogeneous Preference Parameters

\begin{tabular}{|c|c|c|c|c|c|c|c|c|c|c|}
\hline $\begin{array}{l}\text { Model description } \\
\text { Copula family: } \\
\text { Same alpha: } \\
\text { Rho specification: }\end{array}$ & $\begin{array}{c}\text { FGM } \\
\text { No } \\
\text { Standard }\end{array}$ & $\begin{array}{c}\text { Frank } \\
\text { No } \\
\text { Standard }\end{array}$ & $\begin{array}{l}\text { Indp } \\
\text { No } \\
-\end{array}$ & $\begin{array}{c}\text { FGM } \\
\text { Yes } \\
\text { Standard }\end{array}$ & $\begin{array}{c}\text { FGM } \\
\text { Yes } \\
\text { Hetero }\end{array}$ & $\begin{array}{c}\text { FGM } \\
\text { Yes } \\
\text { Restricted }\end{array}$ & $\begin{array}{c}\text { Frank } \\
\text { Yes } \\
\text { Standard }\end{array}$ & $\begin{array}{l}\text { Frank } \\
\text { Yes } \\
\text { Hetero }\end{array}$ & $\begin{array}{c}\text { Frank } \\
\text { Yes } \\
\text { Restricted }\end{array}$ & $\begin{array}{c}\text { Indp } \\
\text { Yes } \\
-\end{array}$ \\
\hline \multicolumn{11}{|l|}{ Parameter } \\
\hline$\beta_{A}=\operatorname{Pr}($ response $\mid \mathrm{A})$ & $\begin{array}{c}0.76 \\
(0.01)\end{array}$ & $\begin{array}{c}0.76 \\
(0.01)\end{array}$ & $\begin{array}{l}0.76 \\
(0.01)\end{array}$ & $\begin{array}{c}0.76 \\
(0.01)\end{array}$ & $\begin{array}{c}0.76 \\
(0.01)\end{array}$ & $\begin{array}{c}0.76 \\
(0.01)\end{array}$ & $\begin{array}{c}0.76 \\
(0.01)\end{array}$ & $\begin{array}{c}0.76 \\
(0.01)\end{array}$ & $\begin{array}{c}0.76 \\
(0.01)\end{array}$ & $\begin{array}{c}0.76 \\
(0.01)\end{array}$ \\
\hline$\beta_{B}=\operatorname{Pr}($ response $\mid \mathrm{B})$ & $\begin{array}{c}0.99 \\
(0.01)\end{array}$ & $\begin{array}{c}0.99 \\
(0.01)\end{array}$ & $\begin{array}{c}0.99 \\
(0.01)\end{array}$ & $\begin{array}{c}0.99 \\
(0.01)\end{array}$ & $\begin{array}{c}0.99 \\
(0.01)\end{array}$ & $\begin{array}{c}0.99 \\
(0.01)\end{array}$ & $\begin{array}{c}0.99 \\
(0.01)\end{array}$ & $\begin{array}{c}0.99 \\
(0.01)\end{array}$ & $\begin{array}{c}0.99 \\
(0.01)\end{array}$ & $\begin{array}{c}0.99 \\
(0.01)\end{array}$ \\
\hline$\gamma / \gamma^{L}$ & $\begin{array}{l}1.08 \\
(0.23)\end{array}$ & $\begin{array}{l}1.08 \\
(0.23)\end{array}$ & $\begin{array}{l}1.07 \\
(0.21)\end{array}$ & $\begin{array}{l}1.09 \\
(0.23)\end{array}$ & $\begin{array}{l}1.09 \\
(0.23)\end{array}$ & $\begin{array}{l}1.09 \\
(0.22)\end{array}$ & $\begin{array}{l}1.10 \\
(0.23)\end{array}$ & $\begin{array}{l}1.10 \\
(0.23)\end{array}$ & $\begin{array}{l}1.08 \\
(0.22)\end{array}$ & $\begin{array}{l}1.08 \\
(0.21)\end{array}$ \\
\hline$\gamma^{C}$ & $\begin{array}{l}1.11 \\
(0.14)\end{array}$ & $\begin{array}{l}1.11 \\
(0.14)\end{array}$ & $\begin{array}{l}1.11 \\
(0.14)\end{array}$ & $\begin{array}{l}1.10 \\
(0.14)\end{array}$ & $\begin{array}{c}1.11 \\
(0.14)\end{array}$ & $\begin{array}{l}1.11 \\
(0.14)\end{array}$ & $\begin{array}{l}1.10 \\
(0.14)\end{array}$ & $\begin{array}{c}1.12 \\
(0.15)\end{array}$ & $\begin{array}{l}1.11 \\
(0.15)\end{array}$ & $\begin{array}{l}1.10 \\
(0.14)\end{array}$ \\
\hline$\gamma^{R}$ & $\begin{array}{c}0.36 \\
(0.13)\end{array}$ & $\begin{array}{c}0.37 \\
(0.13)\end{array}$ & $\begin{array}{l}0.36 \\
(0.13)\end{array}$ & $\begin{array}{c}0.36 \\
(0.13)\end{array}$ & $\begin{array}{c}0.35 \\
(0.13)\end{array}$ & $\begin{array}{c}0.35 \\
(0.13)\end{array}$ & $\begin{array}{c}0.35 \\
(0.13)\end{array}$ & $\begin{array}{c}0.33 \\
(0.14)\end{array}$ & $\begin{array}{c}0.37 \\
(0.13)\end{array}$ & $\begin{array}{c}0.37 \\
(0.13)\end{array}$ \\
\hline$\zeta / \zeta^{L}$ & $\begin{array}{c}0.34 \\
(0.22)\end{array}$ & $\begin{array}{c}0.34 \\
(0.22)\end{array}$ & $\begin{array}{c}0.34 \\
(0.21)\end{array}$ & $\begin{array}{c}0.34 \\
(0.22)\end{array}$ & $\begin{array}{c}0.34 \\
(0.22)\end{array}$ & $\begin{array}{c}0.34 \\
(0.22)\end{array}$ & $\begin{array}{c}0.33 \\
(0.21)\end{array}$ & $\begin{array}{c}0.33 \\
(0.21)\end{array}$ & $\begin{array}{c}0.34 \\
(0.22)\end{array}$ & $\begin{array}{c}0.34 \\
(0.21)\end{array}$ \\
\hline$\zeta^{C}$ & $\begin{array}{c}0.00 \\
(0.49)\end{array}$ & $\begin{array}{c}0.00 \\
(0.49)\end{array}$ & $\begin{array}{c}0.00 \\
(0.48)\end{array}$ & $\begin{array}{c}0.00 \\
(0.48)\end{array}$ & $\begin{array}{c}0.00 \\
(0.47)\end{array}$ & $\begin{array}{c}0.00 \\
(0.47)\end{array}$ & $\begin{array}{c}0.00 \\
(0.49)\end{array}$ & $\begin{array}{c}0.00 \\
(0.45)\end{array}$ & $\begin{array}{c}0.00 \\
(0.45)\end{array}$ & $\begin{array}{c}0.00 \\
(0.49)\end{array}$ \\
\hline$\zeta^{R}$ & $\begin{array}{c}1.03 \\
(0.33)\end{array}$ & $\begin{array}{c}1.03 \\
(0.32)\end{array}$ & $\begin{array}{l}1.00 \\
(0.32)\end{array}$ & $\begin{array}{c}1.02 \\
(0.32)\end{array}$ & $\begin{array}{c}1.04 \\
(0.33)\end{array}$ & $\begin{array}{c}1.02 \\
(0.32)\end{array}$ & $\begin{array}{c}1.03 \\
(0.32)\end{array}$ & $\begin{array}{c}1.10 \\
(0.33)\end{array}$ & $\begin{array}{c}0.98 \\
(0.31)\end{array}$ & $\begin{array}{c}0.98 \\
(0.32)\end{array}$ \\
\hline$\chi / \chi^{L}$ & $\begin{array}{c}0.18 \\
(0.15)\end{array}$ & $\begin{array}{c}0.18 \\
(0.15)\end{array}$ & $\begin{array}{c}0.18 \\
(0.14)\end{array}$ & $\begin{array}{c}0.19 \\
(0.15)\end{array}$ & $\begin{array}{c}0.19 \\
(0.15)\end{array}$ & $\begin{array}{c}0.18 \\
(0.15)\end{array}$ & $\begin{array}{c}0.19 \\
(0.15)\end{array}$ & $\begin{array}{c}0.20 \\
(0.15)\end{array}$ & $\begin{array}{c}0.19 \\
(0.15)\end{array}$ & $\begin{array}{c}0.18 \\
(0.14)\end{array}$ \\
\hline$\chi^{C}$ & $\begin{array}{c}0.02 \\
(0.09)\end{array}$ & $\begin{array}{c}0.02 \\
(0.09)\end{array}$ & $\begin{array}{c}0.02 \\
(0.09)\end{array}$ & $\begin{array}{c}0.03 \\
(0.09)\end{array}$ & $\begin{array}{c}0.03 \\
(0.09)\end{array}$ & $\begin{array}{c}0.03 \\
(0.09)\end{array}$ & $\begin{array}{c}0.02 \\
(0.09)\end{array}$ & $\begin{array}{c}0.04 \\
(0.10)\end{array}$ & $\begin{array}{c}0.04 \\
(0.09)\end{array}$ & $\begin{array}{c}0.02 \\
(0.09)\end{array}$ \\
\hline$\chi^{R}$ & $\begin{array}{l}-0.04 \\
(0.05)\end{array}$ & $\begin{array}{l}-0.04 \\
(0.05)\end{array}$ & $\begin{array}{l}-0.04 \\
(0.05)\end{array}$ & $\begin{array}{l}-0.04 \\
(0.05)\end{array}$ & $\begin{array}{l}-0.04 \\
(0.05)\end{array}$ & $\begin{array}{l}-0.04 \\
(0.05)\end{array}$ & $\begin{array}{l}-0.04 \\
(0.04)\end{array}$ & $\begin{array}{l}-0.05 \\
(0.04)\end{array}$ & $\begin{array}{l}-0.03 \\
(0.05)\end{array}$ & $\begin{array}{l}-0.03 \\
(0.05)\end{array}$ \\
\hline$\phi_{V, 3}$ & $\begin{array}{c}0.38 \\
(0.15)\end{array}$ & $\begin{array}{c}0.37 \\
(0.15)\end{array}$ & $\begin{array}{c}0.40 \\
(0.15)\end{array}$ & $\begin{array}{c}0.37 \\
(0.15)\end{array}$ & $\begin{array}{c}0.37 \\
(0.16)\end{array}$ & $\begin{array}{c}0.36 \\
(0.16)\end{array}$ & $\begin{array}{c}0.36 \\
(0.15)\end{array}$ & $\begin{array}{c}0.36 \\
(0.16)\end{array}$ & $\begin{array}{c}0.40 \\
(0.16)\end{array}$ & $\begin{array}{c}0.40 \\
(0.15)\end{array}$ \\
\hline$\phi_{V, 2}$ & $\begin{array}{c}0.38 \\
(0.32)\end{array}$ & $\begin{array}{c}0.37 \\
(0.32)\end{array}$ & $\begin{array}{c}0.40 \\
(0.31)\end{array}$ & $\begin{array}{c}0.37 \\
(0.29)\end{array}$ & $\begin{array}{c}0.37 \\
(0.30)\end{array}$ & $\begin{array}{c}0.36 \\
(0.29)\end{array}$ & $\begin{array}{c}0.36 \\
(0.28)\end{array}$ & $\begin{array}{c}0.36 \\
(0.28)\end{array}$ & $\begin{array}{c}0.40 \\
(0.30)\end{array}$ & $\begin{array}{c}0.40 \\
(0.28)\end{array}$ \\
\hline$\alpha_{V} / \alpha_{V, 3}$ & $\begin{array}{c}0.59 \\
(0.06)\end{array}$ & $\begin{array}{c}0.58 \\
(0.06)\end{array}$ & $\begin{array}{c}0.59 \\
(0.07)\end{array}$ & $\begin{array}{c}0.56 \\
(0.05)\end{array}$ & $\begin{array}{c}0.56 \\
(0.05)\end{array}$ & $\begin{array}{c}0.56 \\
(0.05)\end{array}$ & $\begin{array}{c}0.56 \\
(0.05)\end{array}$ & $\begin{array}{c}0.56 \\
(0.05)\end{array}$ & $\begin{array}{c}0.56 \\
(0.06)\end{array}$ & $\begin{array}{c}0.56 \\
(0.05)\end{array}$ \\
\hline$\alpha_{V, 2}$ & $\begin{array}{c}0.51 \\
(0.10)\end{array}$ & $\begin{array}{c}0.51 \\
(0.10)\end{array}$ & $\begin{array}{c}0.51 \\
(0.10)\end{array}$ & $\begin{array}{l}- \\
-\end{array}$ & $\begin{array}{l}- \\
-\end{array}$ & - & - & $\begin{array}{l}- \\
-\end{array}$ & $\begin{array}{l}- \\
-\end{array}$ & $\begin{array}{l}- \\
-\end{array}$ \\
\hline$\phi_{P, 3}$ & $\begin{array}{c}0.58 \\
(0.17)\end{array}$ & $\begin{array}{c}0.58 \\
(0.16)\end{array}$ & $\begin{array}{c}0.59 \\
(0.16)\end{array}$ & $\begin{array}{c}0.57 \\
(0.16)\end{array}$ & $\begin{array}{c}0.57 \\
(0.16)\end{array}$ & $\begin{array}{c}0.57 \\
(0.16)\end{array}$ & $\begin{array}{c}0.57 \\
(0.16)\end{array}$ & $\begin{array}{c}0.55 \\
(0.15)\end{array}$ & $\begin{array}{c}0.56 \\
(0.15)\end{array}$ & $\begin{array}{c}0.58 \\
(0.16)\end{array}$ \\
\hline$\phi_{P, 2}$ & $\begin{array}{c}0.38 \\
(0.20)\end{array}$ & $\begin{array}{c}0.38 \\
(0.20)\end{array}$ & $\begin{array}{c}0.38 \\
(0.20)\end{array}$ & $\begin{array}{c}0.37 \\
(0.20)\end{array}$ & $\begin{array}{c}0.36 \\
(0.20)\end{array}$ & $\begin{array}{c}0.37 \\
(0.20)\end{array}$ & $\begin{array}{c}0.37 \\
(0.19)\end{array}$ & $\begin{array}{c}0.33 \\
(0.19)\end{array}$ & $\begin{array}{c}0.37 \\
(0.19)\end{array}$ & $\begin{array}{c}0.38 \\
(0.19)\end{array}$ \\
\hline$\alpha_{P} / \alpha_{P, 3}$ & $\begin{array}{c}0.71 \\
(0.23)\end{array}$ & $\begin{array}{c}0.71 \\
(0.23)\end{array}$ & $\begin{array}{c}0.72 \\
(0.24)\end{array}$ & $\begin{array}{c}0.70 \\
(0.18)\end{array}$ & $\begin{array}{c}0.69 \\
(0.18)\end{array}$ & $\begin{array}{c}0.70 \\
(0.18)\end{array}$ & $\begin{array}{c}0.69 \\
(0.18)\end{array}$ & $\begin{array}{c}0.68 \\
(0.17)\end{array}$ & $\begin{array}{c}0.70 \\
(0.18)\end{array}$ & $\begin{array}{c}0.71 \\
(0.19)\end{array}$ \\
\hline$\alpha_{P, 2}$ & $\begin{array}{c}0.69 \\
(0.30)\end{array}$ & $\begin{array}{c}0.69 \\
(0.30)\end{array}$ & $\begin{array}{c}0.69 \\
(0.30)\end{array}$ & - & - & - & - & - & - & - \\
\hline$\rho_{A} / \rho_{A}^{L}$ & $\begin{array}{l}-1.00 \\
(10.62)\end{array}$ & $\begin{array}{c}-13.67 \\
(261.31)\end{array}$ & $\begin{array}{l}- \\
-\end{array}$ & $\begin{array}{l}-1.00 \\
(10.37)\end{array}$ & $\begin{array}{l}-1.00 \\
(11.69)\end{array}$ & $\begin{array}{l}-1.00 \\
(11.58)\end{array}$ & $\begin{array}{l}-8.24 \\
(90.46)\end{array}$ & $\begin{array}{c}-30.00 \\
(1703.1)\end{array}$ & $\begin{array}{c}-30.00 \\
(1717.1)\end{array}$ & $\begin{array}{l}- \\
-\end{array}$ \\
\hline$\rho_{A}^{C}$ & - & $\begin{array}{l}- \\
-\end{array}$ & - & - & $\begin{array}{c}1.00 \\
(134.16)\end{array}$ & $\begin{array}{c}1.00 \\
(136.54)\end{array}$ & - & $\begin{array}{c}14.17 \\
(4054.00)\end{array}$ & $\begin{array}{c}13.22 \\
(4003.60)\end{array}$ & - \\
\hline$\rho_{A}^{R}$ & $\begin{array}{l}- \\
-\end{array}$ & $\begin{array}{l}- \\
-\end{array}$ & $\begin{array}{l}- \\
-\end{array}$ & $\begin{array}{l}- \\
-\end{array}$ & $\begin{array}{c}1.00 \\
(15.42)\end{array}$ & $\begin{array}{l}- \\
-\end{array}$ & $\begin{array}{l}- \\
-\end{array}$ & $\begin{array}{c}30.00 \\
(786.89)\end{array}$ & $\begin{array}{l}- \\
-\end{array}$ & $\begin{array}{l}- \\
-\end{array}$ \\
\hline$\rho_{B} / \rho_{B}^{L}$ & $\begin{array}{l}-1.00 \\
(18.42)\end{array}$ & $\begin{array}{c}-30.00 \\
(2035.20)\end{array}$ & $\begin{array}{l}- \\
-\end{array}$ & $\begin{array}{l}-1.00 \\
(17.90)\end{array}$ & $\begin{array}{l}-1.00 \\
(18.95)\end{array}$ & $\begin{array}{l}-1.00 \\
(13.53)\end{array}$ & $\begin{array}{c}-30.00 \\
(1952.30)\end{array}$ & $\begin{array}{c}-30.00 \\
(1969.40)\end{array}$ & $\begin{array}{c}-29.99 \\
(1796.20)\end{array}$ & $\begin{array}{l}- \\
-\end{array}$ \\
\hline$\rho_{B}^{C}$ & - & $\begin{array}{l}- \\
-\end{array}$ & $\begin{array}{l}- \\
-\end{array}$ & - & $\begin{array}{c}1.00 \\
(190.48)\end{array}$ & $\begin{array}{c}1.00 \\
(195.53)\end{array}$ & - & $\begin{array}{c}8.43 \\
(2618.30)\end{array}$ & $\begin{array}{c}8.23 \\
(3160.70)\end{array}$ & $\begin{array}{l}- \\
-\end{array}$ \\
\hline$\rho_{B}^{R}$ & - & - & - & - & $\begin{array}{c}-1.00 \\
(42.58)\end{array}$ & - & - & $\begin{array}{c}-30.00 \\
(5325.70)\end{array}$ & - & - \\
\hline $\begin{array}{l}\text { Loglikelihood } \\
\text { Observations }\end{array}$ & $\begin{array}{c}-1043.20 \\
1,306\end{array}$ & $\begin{array}{c}-1042.90 \\
1,306\end{array}$ & $\begin{array}{c}-1043.30 \\
1,306\end{array}$ & $\begin{array}{c}-1043.40 \\
1,306\end{array}$ & $\begin{array}{c}-1043.30 \\
1,306\end{array}$ & $\begin{array}{c}-1043.40 \\
1,306\end{array}$ & $\begin{array}{c}-1043.10 \\
1,306\end{array}$ & $\begin{array}{c}-1042.60 \\
1,306\end{array}$ & $\begin{array}{c}-1043.10 \\
1,306\end{array}$ & $\begin{array}{c}-1043.60 \\
1,306\end{array}$ \\
\hline
\end{tabular}

Notes. Asymptotic standard errors in brackets. Preference parameters are allowed to vary with voter's ideology (L,C,R); based on LR tests, our preferred specification is with independent copula and same alpha. Copula family: "FGM" stands for Farlie-Gumbel-Morgensen; "Frank" stands for Frank family; "Indp" for . Same alpha: "yes" forces skew of marginals to be the same for each level of stated uncertainty; "no" allows the skew to differ. Rho specification: "standard" means baseline $\rho_{A}$ and $\rho_{B}$; "hetero" allows $\rho_{A}$ and $\rho_{B}$ to vary with voter's ideology; "restricted" forces $\rho_{A}^{L}=\rho_{B}^{R}$ and $\rho_{A}^{R}=\rho_{B}^{L}$. 
Table A6 - Model Estimates without Heterogeneous Preference Parameters

\begin{tabular}{|c|c|c|c|c|c|c|c|c|c|c|}
\hline $\begin{array}{l}\text { Model description } \\
\text { Copula family: } \\
\text { Same alpha: } \\
\text { Rho specification: } \\
\text { Parameter }\end{array}$ & $\begin{array}{c}\text { FGM } \\
\text { No } \\
\text { Standard }\end{array}$ & $\begin{array}{c}\text { Frank } \\
\text { No } \\
\text { Standard }\end{array}$ & $\begin{array}{l}\text { Indp } \\
\text { No } \\
-\end{array}$ & $\begin{array}{c}\text { FGM } \\
\text { Yes } \\
\text { Standard }\end{array}$ & $\begin{array}{c}\text { FGM } \\
\text { Yes } \\
\text { Hetero }\end{array}$ & $\begin{array}{c}\text { FGM } \\
\text { Yes } \\
\text { Restricted }\end{array}$ & $\begin{array}{c}\text { Frank } \\
\text { Yes } \\
\text { Standard }\end{array}$ & $\begin{array}{l}\text { Frank } \\
\text { Yes } \\
\text { Hetero }\end{array}$ & $\begin{array}{c}\text { Frank } \\
\text { Yes } \\
\text { Restricted }\end{array}$ & $\begin{array}{c}\text { Indp } \\
\text { Yes } \\
-\end{array}$ \\
\hline$\beta_{A}=\operatorname{Pr}($ response $\mid \mathrm{A})$ & $\begin{array}{c}0.77 \\
(0.01)\end{array}$ & $\begin{array}{c}0.77 \\
(0.01)\end{array}$ & $\begin{array}{c}0.77 \\
(0.01)\end{array}$ & $\begin{array}{c}0.77 \\
(0.01)\end{array}$ & $\begin{array}{c}0.77 \\
(0.01)\end{array}$ & $\begin{array}{c}0.77 \\
(0.01)\end{array}$ & $\begin{array}{c}0.77 \\
(0.01)\end{array}$ & $\begin{array}{c}0.77 \\
(0.01)\end{array}$ & $\begin{array}{c}0.77 \\
(0.01)\end{array}$ & $\begin{array}{c}0.77 \\
(0.01)\end{array}$ \\
\hline$\beta_{B}=\operatorname{Pr}($ response $\mid \mathrm{B})$ & $\begin{array}{c}0.98 \\
(0.01)\end{array}$ & $\begin{array}{c}0.98 \\
(0.01)\end{array}$ & $\begin{array}{c}0.98 \\
(0.01)\end{array}$ & $\begin{array}{c}0.98 \\
(0.01)\end{array}$ & $\begin{array}{c}0.98 \\
(0.01)\end{array}$ & $\begin{array}{c}0.98 \\
(0.01)\end{array}$ & $\begin{array}{c}0.98 \\
(0.01)\end{array}$ & $\begin{array}{c}0.98 \\
(0.01)\end{array}$ & $\begin{array}{c}0.98 \\
(0.01)\end{array}$ & $\begin{array}{c}0.98 \\
(0.01)\end{array}$ \\
\hline$\gamma / \gamma^{L} 0.89$ & $\begin{array}{c}0.91 \\
(0.09)\end{array}$ & $\begin{array}{c}0.90 \\
(0.09)\end{array}$ & $\begin{array}{c}0.88 \\
(0.09)\end{array}$ & $\begin{array}{c}0.88 \\
(0.09)\end{array}$ & $\begin{array}{c}0.90 \\
(0.09)\end{array}$ & $\begin{array}{c}0.91 \\
(0.09)\end{array}$ & $\begin{array}{c}0.91 \\
(0.09)\end{array}$ & $\begin{array}{c}0.91 \\
(0.09)\end{array}$ & $\begin{array}{c}0.89 \\
(0.09)\end{array}$ & $(0.09)$ \\
\hline$\gamma^{C}$ & - & - & - & - & - & - & - & - & - & - \\
\hline$\gamma^{R}$ & - & - & - & - & - & $\begin{array}{l}- \\
-\end{array}$ & $\begin{array}{l}- \\
-\end{array}$ & $\begin{array}{l}- \\
-\end{array}$ & - & - \\
\hline$\zeta / \zeta^{L}$ & $\begin{array}{c}0.65 \\
(0.14)\end{array}$ & $\begin{array}{c}0.68 \\
(0.14)\end{array}$ & $\begin{array}{c}0.69 \\
(0.14)\end{array}$ & $\begin{array}{c}0.69 \\
(0.14)\end{array}$ & $\begin{array}{c}0.68 \\
(0.14)\end{array}$ & $\begin{array}{c}0.65 \\
(0.14)\end{array}$ & $\begin{array}{c}0.66 \\
(0.14)\end{array}$ & $\begin{array}{c}0.66 \\
(0.14)\end{array}$ & $\begin{array}{c}0.68 \\
(0.14)\end{array}$ & $(0.14)$ \\
\hline $\begin{array}{l}\zeta^{C} \\
\zeta^{R}\end{array}$ & $\begin{array}{l}- \\
- \\
-\end{array}$ & $\begin{array}{l}- \\
- \\
-\end{array}$ & $\begin{array}{l}- \\
- \\
-\end{array}$ & $\begin{array}{l}- \\
- \\
-\end{array}$ & $\begin{array}{l}- \\
- \\
-\end{array}$ & $\begin{array}{l}- \\
- \\
-\end{array}$ & $\begin{array}{l}- \\
- \\
-\end{array}$ & $\begin{array}{l}- \\
- \\
-\end{array}$ & $\begin{array}{l}- \\
- \\
-\end{array}$ & $\begin{array}{l}- \\
- \\
-\end{array}$ \\
\hline$\chi / \chi^{L}$ & $\begin{array}{c}- \\
0.05 \\
(0.05)\end{array}$ & $\begin{array}{c}- \\
0.06 \\
(0.05)\end{array}$ & $\begin{array}{c}- \\
0.05 \\
(0.05)\end{array}$ & $\begin{array}{c}- \\
0.04 \\
(0.05)\end{array}$ & $\begin{array}{c}- \\
0.04 \\
(0.05)\end{array}$ & $\begin{array}{c}- \\
0.05 \\
(0.05)\end{array}$ & $\begin{array}{c}- \\
0.06 \\
(0.05)\end{array}$ & $\begin{array}{c}- \\
0.06 \\
(0.05)\end{array}$ & $\begin{array}{c}- \\
0.06 \\
(0.05)\end{array}$ & $\begin{array}{c}- \\
0.05 \\
(0.05)\end{array}$ \\
\hline$\chi^{C}$ & - & - & - & - & $\begin{array}{l}- \\
-\end{array}$ & - & - & - & - & - \\
\hline $\begin{array}{l}\chi^{R} \\
-\end{array}$ & - & - & - & - & - & - & - & - & - & - \\
\hline$\phi_{V, 3}$ & $\begin{array}{c}0.40 \\
(0.17)\end{array}$ & $\begin{array}{c}0.35 \\
(0.16)\end{array}$ & $\begin{array}{c}0.35 \\
(0.15)\end{array}$ & $\begin{array}{c}0.34 \\
(0.15)\end{array}$ & $\begin{array}{c}0.40 \\
(0.17)\end{array}$ & $\begin{array}{c}0.34 \\
(0.17)\end{array}$ & $\begin{array}{c}0.34 \\
(0.16)\end{array}$ & $\begin{array}{c}0.34 \\
(0.16)\end{array}$ & $\begin{array}{c}0.34 \\
(0.16)\end{array}$ & $\begin{array}{c}0.34 \\
(0.16)\end{array}$ \\
\hline$\phi_{V, 2}$ & $\begin{array}{c}0.40 \\
(0.30)\end{array}$ & $\begin{array}{c}0.35 \\
(0.29)\end{array}$ & $\begin{array}{c}0.35 \\
(0.29)\end{array}$ & $\begin{array}{c}0.34 \\
(0.24)\end{array}$ & $\begin{array}{c}0.40 \\
(0.30)\end{array}$ & $\begin{array}{c}0.34 \\
(0.25)\end{array}$ & $\begin{array}{c}0.34 \\
(0.28)\end{array}$ & $\begin{array}{c}0.34 \\
(0.29)\end{array}$ & $\begin{array}{c}0.34 \\
(0.29)\end{array}$ & $\begin{array}{c}0.34 \\
(0.28)\end{array}$ \\
\hline$\alpha_{V} / \alpha_{V, 3}$ & $\begin{array}{c}0.54 \\
(0.07)\end{array}$ & $\begin{array}{c}0.54 \\
(0.06)\end{array}$ & $\begin{array}{c}0.54 \\
(0.06)\end{array}$ & $\begin{array}{c}0.51 \\
(0.05)\end{array}$ & $\begin{array}{c}0.52 \\
(0.06)\end{array}$ & $\begin{array}{c}0.52 \\
(0.05)\end{array}$ & $\begin{array}{c}0.52 \\
(0.05)\end{array}$ & $\begin{array}{c}0.52 \\
(0.05)\end{array}$ & $\begin{array}{c}0.52 \\
(0.05)\end{array}$ & $\begin{array}{c}0.52 \\
(0.05)\end{array}$ \\
\hline$\alpha_{V, 2}$ & $\begin{array}{c}0.50 \\
(0.11)\end{array}$ & $\begin{array}{c}0.50 \\
(0.10)\end{array}$ & $\begin{array}{c}0.50 \\
(0.10)\end{array}$ & - & - & - & - & - & - & - \\
\hline$\phi_{P, 3}$ & $\begin{array}{c}0.60 \\
(0.17)\end{array}$ & $\begin{array}{c}0.58 \\
(0.15)\end{array}$ & $\begin{array}{c}0.61 \\
(0.15)\end{array}$ & $\begin{array}{c}0.65 \\
(0.17)\end{array}$ & $\begin{array}{c}0.65 \\
(0.17)\end{array}$ & $\begin{array}{c}0.60 \\
(0.15)\end{array}$ & $\begin{array}{c}0.61 \\
(0.16)\end{array}$ & $\begin{array}{c}0.58 \\
(0.15)\end{array}$ & $\begin{array}{c}0.62 \\
(0.15)\end{array}$ & $\begin{array}{c}0.65 \\
(0.15)\end{array}$ \\
\hline$\phi_{P, 2}$ & $\begin{array}{c}0.60 \\
(0.33)\end{array}$ & $\begin{array}{c}0.55 \\
(0.32)\end{array}$ & $\begin{array}{c}0.61 \\
(0.32)\end{array}$ & $\begin{array}{c}0.65 \\
(0.27)\end{array}$ & $\begin{array}{c}0.65 \\
(0.28)\end{array}$ & $\begin{array}{c}0.60 \\
(0.26)\end{array}$ & $\begin{array}{c}0.61 \\
(0.26)\end{array}$ & $\begin{array}{c}0.58 \\
(0.27)\end{array}$ & $\begin{array}{c}0.61 \\
(0.26)\end{array}$ & $\begin{array}{c}0.65 \\
(0.26)\end{array}$ \\
\hline$\alpha_{P} / \alpha_{P, 3}$ & $\begin{array}{c}0.80 \\
(0.26)\end{array}$ & $\begin{array}{c}0.77 \\
(0.23)\end{array}$ & $\begin{array}{c}0.81 \\
(0.27)\end{array}$ & $\begin{array}{c}0.81 \\
(0.28)\end{array}$ & $\begin{array}{c}0.82 \\
(0.28)\end{array}$ & $\begin{array}{c}0.77 \\
(0.22)\end{array}$ & $\begin{array}{c}0.77 \\
(0.23)\end{array}$ & $\begin{array}{c}0.74 \\
(0.20)\end{array}$ & $\begin{array}{c}0.77 \\
(0.23)\end{array}$ & $\begin{array}{c}0.81 \\
(0.27)\end{array}$ \\
\hline$\alpha_{P, 2}$ & $\begin{array}{c}0.69 \\
(0.42)\end{array}$ & $\begin{array}{c}0.65 \\
(0.35)\end{array}$ & $\begin{array}{c}0.70 \\
(0.44)\end{array}$ & - & - & - & - & - & - & - \\
\hline$\rho_{A} / \rho_{A}^{L}$ & $\begin{array}{l}-1.00 \\
(18.09)\end{array}$ & $\begin{array}{c}-30.00 \\
(1993.00)\end{array}$ & $\begin{array}{l}- \\
-\end{array}$ & $\begin{array}{l}-1.00 \\
(22.79)\end{array}$ & $\begin{array}{l}-1.00 \\
(38.48)\end{array}$ & $\begin{array}{c}1.00 \\
(24.90)\end{array}$ & $\begin{array}{c}-30.00 \\
(2120.70)\end{array}$ & $\begin{array}{c}-30.00 \\
(3038.50)\end{array}$ & $\begin{array}{c}29.99 \\
(2786.20)\end{array}$ & - \\
\hline$\rho_{A}^{C}$ & - & $\begin{array}{l}- \\
-\end{array}$ & $\begin{array}{l}- \\
-\end{array}$ & - & $\begin{array}{c}1.00 \\
(53.29)\end{array}$ & $\begin{array}{c}1.00 \\
(41.32)\end{array}$ & - & $\begin{array}{c}30.00 \\
(1849.70)\end{array}$ & $\begin{array}{c}29.60 \\
(7268.40)\end{array}$ & $\begin{array}{l}- \\
-\end{array}$ \\
\hline$\rho_{A}^{R}$ & $\begin{array}{l}- \\
-\end{array}$ & $\begin{array}{l}- \\
-\end{array}$ & $\begin{array}{l}- \\
-\end{array}$ & $\begin{array}{l}- \\
-\end{array}$ & $\begin{array}{l}-1.00 \\
(41.50)\end{array}$ & $\begin{array}{l}- \\
-\end{array}$ & $\begin{array}{l}- \\
-\end{array}$ & $\begin{array}{c}-30.00 \\
(2997.90)\end{array}$ & - & $\begin{array}{l}- \\
-\end{array}$ \\
\hline$\rho_{B} / \rho_{B}^{L}$ & $\begin{array}{c}1.00 \\
(29.21)\end{array}$ & $\begin{array}{c}29.99 \\
(1633.70)\end{array}$ & $\begin{array}{l}- \\
-\end{array}$ & $\begin{array}{c}1.00 \\
(37.36)\end{array}$ & $\begin{array}{l}-1.00 \\
(51.93)\end{array}$ & $\begin{array}{l}-1.00 \\
(22.23)\end{array}$ & $\begin{array}{c}29.99 \\
(3674.60)\end{array}$ & $\begin{array}{c}-30.00 \\
(4066.60)\end{array}$ & $\begin{array}{c}-30.00 \\
(2467.70)\end{array}$ & $\begin{array}{l}- \\
-\end{array}$ \\
\hline$\rho_{B}^{C}$ & - & - & $\begin{array}{l}- \\
-\end{array}$ & - & $\begin{array}{c}1.00 \\
(86.81)\end{array}$ & $\begin{array}{c}1.00 \\
(63.35)\end{array}$ & - & $\begin{array}{c}22.42 \\
(6915.90)\end{array}$ & $\begin{array}{c}27.94 \\
(11627.00)\end{array}$ & $\begin{array}{l}- \\
-\end{array}$ \\
\hline$\rho_{B}^{R}$ & - & - & - & - & $\begin{array}{c}-1.00 \\
(81.43)\end{array}$ & $\begin{array}{l}- \\
-\end{array}$ & - & $\begin{array}{c}-30.00 \\
(7895.00)\end{array}$ & $\begin{array}{l}- \\
-\end{array}$ & - \\
\hline $\begin{array}{l}\text { Loglikelihood } \\
\text { Observations }\end{array}$ & $\begin{array}{c}-1057.70 \\
1,306\end{array}$ & $\begin{array}{c}-1057.40 \\
1,306\end{array}$ & $\begin{array}{c}-1057.70 \\
1,306\end{array}$ & $\begin{array}{c}-1057.90 \\
1,306\end{array}$ & $\begin{array}{c}-1057.94 \\
1,306\end{array}$ & $\begin{array}{c}-1057.70 \\
1,306\end{array}$ & $\begin{array}{c}-1057.50 \\
1,306\end{array}$ & $\begin{array}{c}-1057.50 \\
1,306\end{array}$ & $\begin{array}{c}-1057.40 \\
1,306\end{array}$ & $\begin{array}{c}-1057.90 \\
1,306\end{array}$ \\
\hline
\end{tabular}

$\overline{\text { Notes. Asymptotic standard errors in brackets. Unlike Table A3, preference parameters are not allowed to vary with voter's ideology (L,C,R); }}$ based on LR tests, these are not our preferred specifications but we report them for completeness. Copula family: "FGM" stands for FarlieGumbel-Morgensen; "Frank" stands for Frank family; "Indp" for . Same alpha: "yes" forces skew of marginals to be the same for each level of stated uncertainty; "no" allows the skew to differ. Rho specification: "standard" means baseline $\rho_{A}$ and $\rho_{B}$; "hetero" allows $\rho_{A}$ and $\rho_{B}$ to vary with voter's ideology; "restricted" forces $\rho_{A}^{L}=\rho_{B}^{R}$ and $\rho_{A}^{R}=\rho_{B}^{L}$. 
Table A7 - LR Tests: Restriction of Preference Parameters

To Be the Same across Voter's Ideology

\begin{tabular}{lcc}
\hline \hline Copula & Test statistic & P-value \\
\hline FGM & 28.94 & 0.00 \\
Frank & 28.86 & 0.00 \\
Independent & 28.62 & 0.00 \\
\hline \hline Notes, Skew restricted to be the same across levels of stated uncertainty & Standard $\rho$ specification
\end{tabular}

Table A8 - LR Tests: Restriction of Skew

To Be the Same across Levels of Uncertainty

\begin{tabular}{lccc}
\hline \hline Preferences & Copula & Test statistic & P-value \\
\hline Homogeneous & FGM & 0.29 & 0.86 \\
Homogeneous & Frank & 0.37 & 0.83 \\
Homogeneous & Indp & 0.38 & 0.83 \\
Heterogeneous & FGM & 0.49 & 0.78 \\
Heterogeneous & Frank & 0.39 & 0.82 \\
Heterogeneous & Indp & 0.54 & 0.76 \\
\hline Notes. Standard $\rho$ specification. & & &
\end{tabular}

Notes. Standard $\rho$ specification.

Table A9 - Vuong Tests: Copula Comparisons

\begin{tabular}{|c|c|c|c|c|c|}
\hline Preferences & $\begin{array}{c}\text { Copula } \\
\text { comparison }\end{array}$ & $\begin{array}{c}\text { Rho } \\
\text { specification }\end{array}$ & $\begin{array}{c}\text { Test } \\
\text { statistic }\end{array}$ & $\mathrm{P}$-value & $\begin{array}{l}\text { Preferred } \\
\text { copula }\end{array}$ \\
\hline Homogeneous & Frank vs. FGM & Standard & 0.76 & 0.45 & Frank \\
\hline Homogeneous & Independent vs. FGM & Standard & 39.48 & 0.00 & Independent \\
\hline Homogeneous & Independent vs. Frank & Standard & 17.93 & 0.00 & Independent \\
\hline Heterogeneous & Frank vs. FGM & Standard & 1.05 & 0.29 & Frank \\
\hline Heterogeneous & Independent vs. FGM & Standard & 22.67 & 0.00 & Independent \\
\hline Heterogeneous & Independent vs. Frank & Standard & 12.61 & 0.00 & Independent \\
\hline Heterogeneous & Independent vs. FGM & Heterogeneous & 52.08 & 0.00 & Independent \\
\hline Heterogeneous & Independent vs. Frank & Heterogeneous & 26.59 & 0.00 & Independent \\
\hline Homogeneous & Independent vs. FGM & Heterogeneous & 12.9 & 0.00 & Independent \\
\hline Homogeneous & Independent vs. Frank & Heterogeneous & 35.93 & 0.00 & Independent \\
\hline Heterogeneous & Independent vs. FGM & Restricted & 37.19 & 0.00 & Independent \\
\hline Heterogeneous & Independent vs. Frank & Restricted & 30.78 & 0.00 & Independent \\
\hline Homogeneous & Independent vs. FGM & Restricted & 40.57 & 0.00 & Independent \\
\hline Homogeneous & Independent vs. Frank & Restricted & 34.77 & 0.00 & Independent \\
\hline
\end{tabular}

Notes. Skew restricted to be the same across level of stated uncertainty. 
Figure A1 - Campaign Flyer with the Valence Message

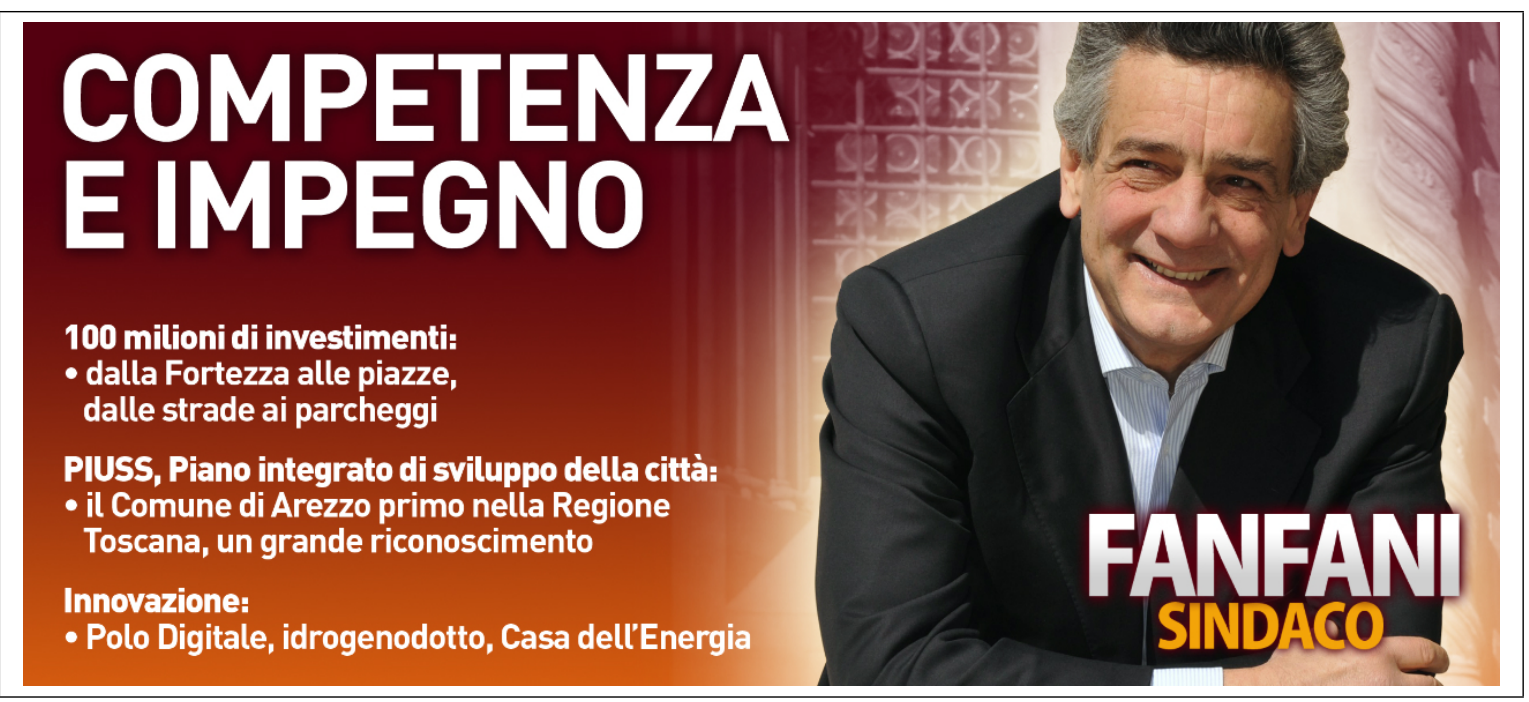

Figure A2 - Campaign Flyer with the Ideology Message

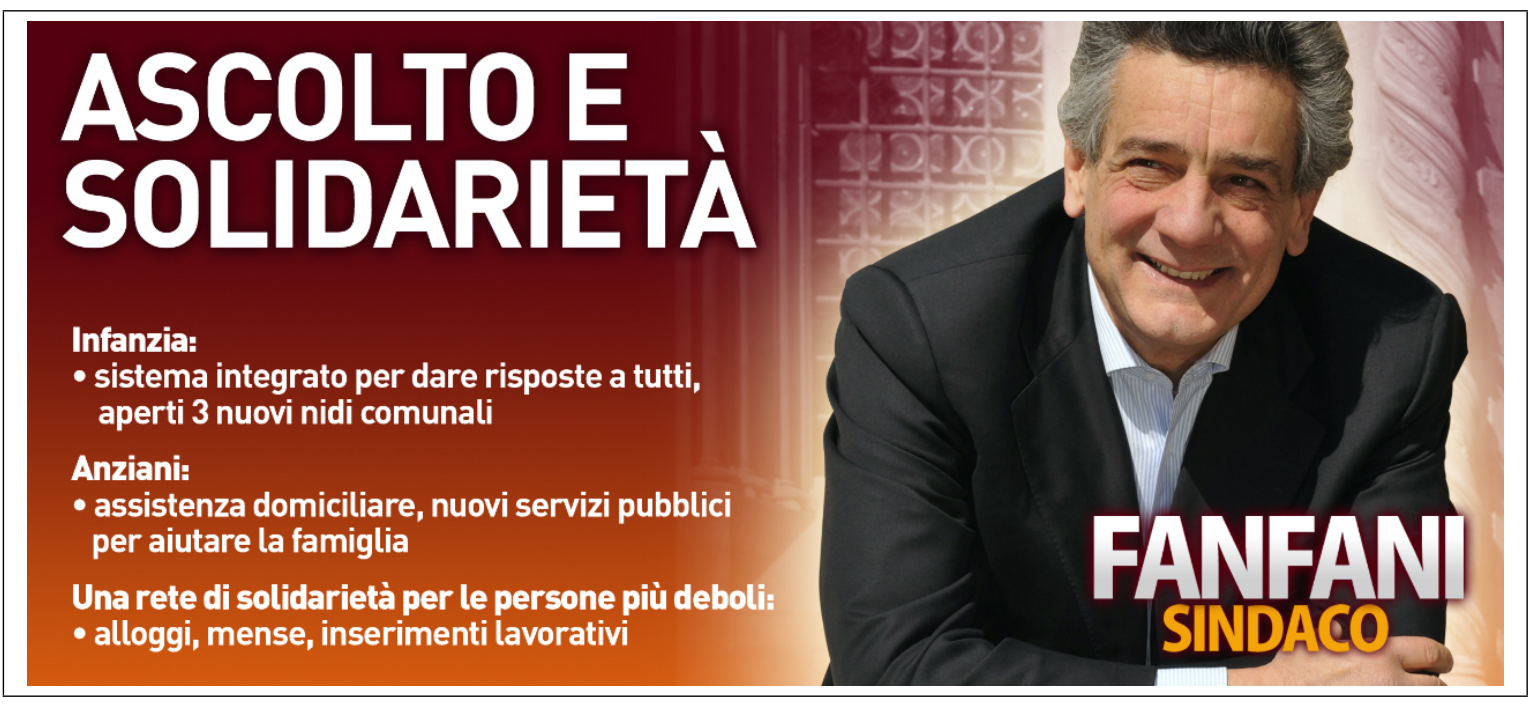

